\title{
Venous Thromboembolism in Cancer Patients Undergoing Major Abdominal Surgery: Prevention and Management
}

\author{
Bhavana Bhagya Rao, ${ }^{1}$ R. Kalayarasan, ${ }^{2}$ Vikram Kate, ${ }^{3}$ and N. Ananthakrishnan ${ }^{4}$ \\ ${ }^{1}$ Department of Gastroenterology, MD Anderson Cancer Center, University of Texas, Houston, TX, USA \\ ${ }^{2}$ Department of Surgical Gastroenterology, GB Pant Hospital, New Delhi, India \\ ${ }^{3}$ Department of General and Gastrointestinal Surgery, Jawaharlal Institute of Postgraduate Medical Education and Research, \\ Pondicherry, India \\ ${ }^{4}$ Department of Surgery, Mahatma Gandhi Medical College \& Research Institute, Pondicherry 607402, India
}

Correspondence should be addressed to N. Ananthakrishnan, n.ananthk@gmail.com

Received 16 February 2012; Accepted 19 March 2012

Academic Editors: A. Hirata and B. Meloni

Copyright ( 2012 Bhavana Bhagya Rao et al. This is an open access article distributed under the Creative Commons Attribution License, which permits unrestricted use, distribution, and reproduction in any medium, provided the original work is properly cited.

Cancer is an important risk factor for venous thrombosis. Venous thromboembolism is one of the most common complications of cancer and the second leading cause of death in these patients. Recent research has given insight into mechanism and various risk factors in cancer patients which predispose to thromboembolism. The purpose of this review is to summarize the current knowledge on the prophylaxis, diagnosis, and management of venous thromboembolism in these patients.

\section{Introduction}

Professor Armand Trousseau was the first to write about the association between cancer and thrombosis in 1865 , and the combination of the two conditions is still often called Trousseau's syndrome [1]. Cancer is an important risk factor for arterial and, more commonly, venous thromboembolism (VTE), which is a spectrum of disease that includes deep venous thrombosis (DVT) and pulmonary embolism (PE). VTE in cancer has an increased incidence due to presence of large number of associated risk factors. Prevention and management of VTE are more challenging in cancer patients in view of the unique pathogenesis, increased rate of complications, and recurrent VTE.

Of all the etiological and predisposing factors, cancer alone was associated with a 4.1 -fold risk of thrombosis, and this risk increases to 6.5 fold in cancer patients on chemotherapy $[2,3]$. Recent studies have reported an overall sevenfold increase in risk of VTE in cancer patients, with the exact risk varying depending on the primary site of cancer-1.6 fold in head and neck cancers and 28 fold in hematological cancers $[4,5]$.
Cancer patients undergoing surgery have twice the risk of postoperative VTE and nonfatal pulmonary embolism (PE) and three times the risk of fatal PE, compared to patients undergoing surgery for benign disease, despite the use of thromboprophylaxis [6-8]. In the RISTOS project, a webbased prospective registry, 2372 patients undergoing general, urologic, or gynecologic surgery for cancer were evaluated [9]. Of these, $82 \%$ had received in-hospital VTE prophylaxis, yet the incidence of clinically overt VTE and fatal VTE was $2.1 \%$ and $0.8 \%$, respectively. Significantly, most VTE events occurred after hospital discharge, and VTE was found to be the most common cause of death at 30 days postoperatively [9].

It is a matter of concern to note that the likelihood of death in cancer patients with VTE is greater than that of patients with cancer or VTE alone [10,11]. Moreover, in cancer patients, the possibility of complications such as anticoagulant failure, bleeding, and recurrent VTE is also higher than in patients without cancer [7, 8, 12-15].

Large population-based studies have suggested that the incidence of VTE is on the rise, among the general popula- 
tion as well as the cancer-affected subgroup $[2,16]$. A retrospective cohort study conducted using the discharge database of the University Health System Consortium between 1995 and 2003 reported that the increase in incidence of DVT and $\mathrm{PE}$ over the years was associated with black ethnicity, use of chemotherapy and also varied with the site of cancer [17].

Since VTE is becoming an increasingly frequent complication in cancer patients and contributes significantly to the morbidity and mortality among those cancer patients who are undergoing surgery, it is important to review the various aspects of its pathogenesis, prevention, and treatment.

\section{Pathogenesis}

There are several mechanisms due to which cancer patients are hypercoagulable, thus predisposing them to arterial and venous thromboses. The intrinsic tumor-related factors include interaction of cancer cells with monocytes and macrophages, causing release of cytokines like TNF, IL-1, and IL-6 which cause damage to the endothelial surfaces making them thrombogenic [18]. Another mechanism is by activation of the coagulation pathway. This is chiefly mediated by the expression of tissue factor (TF) on the epithelial surfaces which have undergone malignant transformation [19-21]. This glycoprotein is a procoagulant, and it has been identified to bind and activate factor VII, which in turn triggers the coagulation cascade by activating factor $\mathrm{X}$ and factor II [19, 22-27]. Cysteine proteases released from tumor cells also have procoagulant properties and cause direct activation of factor X [28-31]. In adenocarcinomas nonenzymatic activation of factor $\mathrm{X}$ occurs due to interaction with the sialic acid moieties of the mucin [32]. In addition activation of platelets (leading to aggregation) and endothelial cells (leading to overexpression of plasminogen activator inhibitor-1) and inhibition of the synthesis of anticoagulation proteins in the liver further cause dysregulation of the coagulation cascade [33-37].

Extrinsic factors such as chemotherapeutic and antiangiogenic agents also contribute to the prothrombotic state by various mechanisms $[38,39]$. Chemotherapeutic drugs have been reported to damage the vascular endothelium, activate platelets, cause induction of TF in tumor cells, and downregulate anticoagulant proteins like protein $\mathrm{C}$ and $\mathrm{S}$ [40-44].

\section{Risk Factors for Venous Thromboembolism in Cancer Patients}

The factors that increase the risk for VTE in cancer patients may be identified to be either tumor, patient, or treatment related [45]. Tumor-related characteristics include tumor type, site, stage of disease, and duration of cancer. As per studies, the cancer types associated with the greatest risk for VTE are adenocarcinomas of the pancreas and stomach, gynecologic and hematologic malignancies, and malignant tumors of the brain, bone, lung, and kidney $[9,10,16,17,46-$ 52]. The role of extent of the disease as a potential risk factor was analyzed in a study conducted over a large cohort of 66,
329 oncologic patients. It reported a 1.9-fold increased risk for VTE in patients with metastases [48]. Similar findings of increased risk of VTE among cancer patients with metastatic disease were also reported by other studies [46, 47, 50-52].

Patient-related factors include advanced age, female gender, black ethnicity, previous history of VTE, the presence of comorbid conditions (obesity, infection, renal disease, pulmonary disease, congestive heart failure, transfusion, and prothrombotic mutations) $[9,16,17,46,47,51-60]$. Treatmentrelated characteristics include current hospitalization, pharmacologic measures such as chemotherapeutic agents, hormonal agents, antiangiogenic agents, and erythropoiesisstimulating agents (ESAs) and mechanical interventions such as surgery and use of central venous catheters $[9,46,48-$ 50, 53, 55-57, 61-80].

Predictive models for VTE have been designed which assign scores appropriate to the odds ratio of some of the most important risk factors, and thus cumulative risk can be calculated for each patient $[81,82]$. The model developed by Khorana et al. shows platelet count $\geq 350000 / \mathrm{mm}^{3}$, hemoglobin concentration $<10 \mathrm{~g} / \mathrm{dL}$, and leukocyte count $>11000 / \mathrm{mm}^{3}$ as promising predictive markers for VTE in oncologic patients [82]. The risk of recurrent VTE is also higher among patients with malignancy when compared to those without cancer $[8,10,83-85]$. The recurrence risk for VTE among oncologic patients is twice as high as compared to that for healthy controls, and if the patient is receiving chemotherapy, the risk increases to four times higher [83]. This risk is reported to be fivefold higher in cancer patients with metastases while in those with localized disease the recurrence risk is two-to threefold [8].

\section{Need for Primary Prevention and Modalities Available}

It has been well established that the risk of postoperative VTE is almost two times greater among cancer patients than noncancer patients undergoing similar surgical procedures, despite the use of prophylaxis [86]. Without prophylaxis the risk of VTE in cancer patients undergoing surgery has been estimated to be as high as $50 \%$, and VTE was found to be the most common cause of death in this group of patients at 30 days after surgery $[9,86]$. Postoperative pharmacologic prophylaxis with anticoagulants for 1-2 weeks after major abdominal or pelvic cancer surgery can reduce the risk of VTE to $1.3 \%$ for symptomatic deep vein thrombosis (DVT) and $0.4 \%$ for fatal pulmonary embolism $[87,88]$. Thus, it is evident from these data that effective thromboprophylaxis is imperative in cancer patients undergoing surgery [89]. The different modalities available for prevention and treatment are listed in Table 1.

\section{Pharmacologic Prophylaxis}

5.1. Aspirin. Aspirin is a nonsteroidal anti-inflammatory drug which is found to be beneficial in preventing major thrombotic vascular events in patients with atherosclerotic disease due to its antiplatelet action. But, in prevention 
TABLE 1: Modalities for prevention and treatment of DVT.

\begin{tabular}{lll}
\hline \multicolumn{2}{l}{ Older agents } & \multicolumn{1}{l}{ Mechanical prophylaxis } \\
\hline (i) Aspirin & (i) Factor Xa inhibitor & (i) Graduated compression stockings (GCS) \\
(ii) Warfarin & fondaparinux & (ii) Venous foot pump devices \\
(iii) Unfractionated heparin (UFH) & idrabiotaparinux & (iii) Electrical calf stimulation \\
(iv) Low molecular weight heparin (LMWH) & idraparinux & (iv) Intermittent pneumatic compression devices \\
$\quad$ dalteparin & rivaroxaban & \\
enoxaparin sodium & apixaban & \\
tinzaparin & (ii) Direct thrombin inhibitor (DTI) & \\
nadroparin sodium & dabigatran & \\
bemiparin & & \\
\hline
\end{tabular}

of VTE in hospitalized patients, only limited evidence is available regarding its protective role [86]. Hence aspirin is not recommended as a primary modality of pharmacoprophylaxis by any of the guidelines.

5.2. Warfarin. Warfarin is a vitamin $\mathrm{K}$ antagonist (VKA) and interferes with the synthesis of clotting factors and thus prevents thrombosis. For over 50 years it formed an integral part of the standard anticoagulation regimen for prophylaxis and treatment of VTE. But its use has been gradually replaced by Unfractionated Heparin (UFH) and now Low Molecular Weight Heparin (LMWH). This is because, although efficacious, the use of warfarin therapy is particularly challenging for clinicians and patients in the oncologic setting. Its anticoagulant effect is of delayed onset and prolonged duration, with clearance furthered lowered in patient with hepatic insufficiency thus necessitating frequent blood sampling for laboratory monitoring in an attempt to maintain adequate, but not excessive dosing [90-93]. Achievement and maintenance of the target international normalized ration (INR) with oral warfarin is more difficult in cancer patients due to concomitant anorexia and emesis [94, 95]. Warfarin's pharmacokinetics is also influenced by diet, and other medications besides interindividual variation $[91,96]$. The need for frequent invasive procedures in some cancer patients (e.g., therapeutic paracentesis) results in interruption of anticoagulation leading to erratic INRs [91]. Warfarin pharmacokinetics is altered by interaction with chemotherapeutic agents, particularly 5 fluorouracil, fluoropyrimidines, capecitabine, erlotinib, and sorafenib leading to elevation in INR value and predisposition to bleeding [97-103]. Also cancer patients on warfarin are reported to develop recurrent thrombosis and bleeding manifestations, more frequently when compared to patients without cancer, despite close maintenance of target INR in both groups [104, 105].

5.3. Unfractionated Heparin. Unfractionated heparin (UFH) consists of a heterogenous mixture of sulphated mucopolysaccharides ranging from 3000 to 30,000 Daltons in molecular weight [106]. Some of these molecules possess a pentasaccharide sequence which binds and activates antithrombin
III in the plasma. This complex then inhibits the action of activated thrombin (factor IIa) and factor Xa and thus mediates an anticoagulant effect. UFH can be administered by either continuous intravenous infusion or by subcutaneous injection, and its effects can be rapidly and completely reversed by infusion of protamine sulfate $[106,107]$.

In an early prospective randomized controlled trial conducted in 178 surgical patients, using UFH as the drug for primary prophylaxis against DVT, the group treated with UFH had a $13.3 \%$ incidence of DVT, whereas in the control group it was $35.8 \%(P<0.001)$ [108]. Further analysis revealed a $25 \%$-relative risk reduction in patients without cancer and a 55\% relative risk reduction in patients with cancer [108]. In a similar prospective controlled study conducted in 820 surgical patients, the incidence of VT in controls was $16 \%$, while in the treated patients it was $4.2 \%$, with a slight increase in minor complications reported in the treated group. Subgroup analysis showed a relative risk reduction of $18 \%$ in patients without cancer and a 39\% relative risk reduction in cancer patients [109]. Thus these early trials and subsequent meta-analyses and multicentre trials strongly emphasized the benefit of UFH prophylaxis in surgical patients, especially in those patients who had concomitant cancer $[89,110]$.

Despite its documented efficacy in this group of patients, certain disadvantages limit the use of UFH. The pharmacokinetics of UFH are unpredictable and influenced by its binding to plasma proteins, endothelial cell surfaces, macrophages, and other acute phase reactants, thus causing variability in the anticoagulant response, which necessitates monitoring of Activated Partial Thromboplastin Time (APTT) values in patients $[106,107]$. Also the interaction of UFH molecules with platelet factor 4 and generation of heparin-dependent IgG antibodies can lead to an immunemediated complication-heparin-induced thrombocytopenia (HIT), where release of procoagulant microparticles such as thrombin occurs into the systemic circulation leads to disseminated arterial and venous thrombosis [111].

5.4. Low Molecular Weight Heparin. Low-molecular-weight heparin $(\mathrm{LMWH})$ is obtained by alkaline degradation of heparin benzyl ester and consists of molecules enriched 
with short chains. LMWH has a molecular weight of 40005000 Dalton with a higher anti-Xa:IIa ratio [106]. Due its higher bioavailability ( $90 \%$ versus $30 \%$ ), longer halflife ( 4 to 6 hours versus 0.5 to 1 hour), predictable and reproducible anticoagulant response, minimal interaction with non-anticoagulant related plasma proteins, and lesser propensity to cause heparin-induced thrombocytopenia and osteoporosis, LMWH has gained popularity over UFH for use in primary and secondary VTE prophylaxis [106, 112]. Some of the routinely prescribed LMWHs include dalteparin, enoxaparin sodium, tinzaparin, nadroparin sodium, and bemiparin.

In practice, the reports from early trials comparing the efficacy and safety of LMWH and UFH suggested no significant difference in the incidence of VTE, minor and major bleeding events and death among the two groups $[88,113-122]$. A meta-analysis, conducted in 2001, found that, in comparison with placebo or no treatment, LMWH was associated with a significant reduction in clinical VTE in a population of patients undergoing general surgery [123]. When compared with UFH a significant reduction in clinical VTE $(P=.049)$ was found in favor of LMWH. This trend was also reflected among in patients undergoing surgery for cancer [123]. A systematic review and meta-analysis published in 2008 which included 14 trials comparing LMWH with UFH for thromboprophylaxis in patients with cancer undergoing surgery concluded that there was no significant survival benefit for LMWH compared with UFH [124]. The same group published another review and meta-analysis in 2011 which included 16 such trials and reported that no significant difference was found between perioperative thromboprophylaxis with LMWH versus UFH in their effects on mortality and embolic outcomes in patients with cancer [125]. The trials in which the study population was cancer patients undergoing major abdominal surgery are listed in Table 2.

With regard to LMWH dosage, a study was conducted comparing 2500 and 5000 units of dalteparin in 2070 patients undergoing abdominal surgery ( $66.4 \%$ of whom had cancer) [126]. Among patients with malignancy, the incidence of DVT was significantly lower in patients given higher dose of dalteparin $(8.5 \%$ versus $14.9 \%, P<0.001)$. Overall, the frequency of bleeding complications was greater in the group which received high-dose dalteparin $(4.7 \%$ versus $2.7 \%, P=$ 0.02 ) but among the patients with malignancy there was no significant difference $(4.6 \%$ versus $3.6 \%, P>0.05)$. Currently most guidelines recommend the use of $5000 \mathrm{U}$ of dalteparin for prophylaxis [127-134]. The drawbacks of LMWHs include the need for daily injection leading to higher direct costs although in comparison to UFH the overall costs are lower as they can be administered at home [112].

5.5. Factor Xa Inhibitors. Factor-specific anticoagulants such as factor Xa inhibitors have emerged as treatment alternatives to heparin and warfarin after being proven to be safe and effective. Factor Xa inhibitors are synthetic derivatives of the antithromin-binding pentasaccharide moiety found in
UFH and LMWH. They mediate an anticoagulant effect by selective inhibition of factor $\mathrm{Xa}$ and are administered subcutaneously at a dose of $2.5 \mathrm{mg}$ for pharmacoprophylaxis of VTE [106]. Currently, three factor Xa inhibitors have been identified: fondaparinux (the only one approved so far by the US Food and Drug Administration), idrabiotaparinux, and idraparinux (both in clinical trials) [134].

The important randomized studies done in surgical patients to evaluate the efficacy of fondaparinux are summarised in Table 3. In a double-blinded randomized trial conducted in 2007, a VTE rate reduction of $69.8 \%$ was demonstrated with use of fondaparinux and intermittent pneumatic compression (IPC) in patients who underwent major abdominal surgery ( $40 \%$ of patients were operated for cancer) when compared to treatment with IPC alone [135]. In another large randomized trial known as PEGASUS22, the efficacy and safety profiles of fondaparinux were compared with dalteparin in 2048 patients who underwent major abdominal surgery [136]. Subgroup analysis of the study's 1408 patients who underwent surgery for cancer showed rates of VTE for fondaparinux and dalteparin group to be $4.7 \%$ and $7.7 \%$, respectively, with a relative risk reduction of $38.6 \%$ while for the entire PEGASUS population the relative risk reduction with fondaparinux was $24.6 \%$. Incidence of major bleeding in the cancer subgroup was comparable between the two treatments.

The likelihood for development of heparin-induced thrombocytopenia (HIT) is low with the use of fondaparinux, and some case series also report treatment of HIT with $7.5 \mathrm{mg}$ of fondaparinux $[137,138]$. The National Comprehensive Cancer Network (NCCN) guidelines consider the use of fondaparinux for treatment of HIT as unlabeled use [130]. The American College of Chest Physicians (ACCPs) guidelines suggest that direct thrombin inhibitor (DTI) is to be used for initial treatment of HIT. Once the platelets levels recover this is to be replaced by therapeutic doses of fondaparinux and gradual bridging to warfarin therapy be done [139]. As majority of these trials and case series have been performed on noncancer patients, fondaparinux should be cautiously used for treatment of HIT in cancer patients, until further supporting evidence is available.

5.6. Newer Agents for Anticoagulation. Currently several new agents for VTE prophylaxes have been introduced into clinical practice or are in the final stages of development and testing. These include dagibatran, an oral direct thrombin inhibitor (DTI) which has been evaluated against enoxaparin in the BISTRO II, RE-MODEL, RE-NOVATE and REMOBILIZE trials, conducted in orthopedic surgical patients and was shown to be noninferior to enoxaparin in its efficacy and safety [140-143]. Rivaroxaban, an oral direct factor Xa inhibitor was also compared to enoxaparin in a similar patient group in the ODIXa-OD-HIP and RECORD 1-4 trials and showed superior reduction in risk of VTE with no significant increase in risk of major postoperative bleeding [144-148]. Apixaban, another oral inhibitor of factor Xa, is being evaluated in patients with cancer in ongoing trials $[149,150]$. 
TABLE 2: Studies evaluating venous thromboembolism (VTE) prophylaxis with LMWH and UFH in cancer patients undergoing major abdominal surgery.

\begin{tabular}{|c|c|c|c|c|c|c|c|c|}
\hline \multirow{2}{*}{ Trial } & \multirow{2}{*}{ Method } & \multirow{2}{*}{ Patients $(n)$} & \multirow{2}{*}{ Study population } & \multicolumn{2}{|c|}{ Regimen } & \multirow{2}{*}{ Followup } & \multicolumn{2}{|c|}{ Incidence of VTE } \\
\hline & & & & Study & Control & & $\begin{array}{c}\text { Study } \\
(\%)\end{array}$ & $\begin{array}{c}\text { Control } \\
(\%)\end{array}$ \\
\hline $\begin{array}{l}\text { Bergqvist et al. } \\
1990 \text { [246] }\end{array}$ & $\begin{array}{l}\text { Randomise } \\
\text { double } \\
\text { blind-trial }\end{array}$ & 637 & $\begin{array}{l}\text { Patients with cancer } \\
\text { (study subgroup) } \\
\text { undergoing abdominal } \\
\text { surgery }\end{array}$ & $\begin{array}{l}\text { Dalteparin } 5000 \\
\text { Units } \\
\text { preoperatively then } \\
\text { q.d. } \times 5-8 \text { days }\end{array}$ & $\begin{array}{l}\text { UFH } 5000 \\
\text { Units } 2 \text { h pre- } \\
\text { operatively } \\
\text { then b.d. } \times \\
5-8 \text { days }\end{array}$ & 7 days & 6.4 & 11.2 \\
\hline EFS 1988 [120] & $\begin{array}{c}\text { Randomised } \\
\text { trial }\end{array}$ & 704 & $\begin{array}{l}\text { Patients with cancer } \\
\text { (study subgroup) } \\
\text { scheduled for elective } \\
\text { abdominal surgery }\end{array}$ & $\begin{array}{l}\text { Fraxiparin } 7500 \\
\text { anti-Xa units } \\
\text { preoperatively then } \\
\text { q.d. } \times 7 \text { days }\end{array}$ & $\begin{array}{l}\text { Calcium } \\
\text { heparin } 5000 \\
\text { units preop- } \\
\text { eratively then } \\
\text { t.i.d } \times 7 \text { days }\end{array}$ & 7 days & & \\
\hline $\begin{array}{l}\text { Enoxacan } 1997 \\
{[229]}\end{array}$ & $\begin{array}{l}\text { Double-blind } \\
\text { randomised trial }\end{array}$ & 631 & $\begin{array}{l}\text { Patients undergoing } \\
\text { planned curative } \\
\text { abdominal or pelvic } \\
\text { surgery for cancer (study } \\
\text { subgroup) }\end{array}$ & $\begin{array}{l}\text { Enoxaparin } 40 \mathrm{mg} \\
\text { q.d. } \times 10 \text { days }\end{array}$ & $\begin{array}{l}\text { Low-dose } \\
\text { UFH t.i.d } \times \\
10 \text { days }\end{array}$ & 3 months & 14.7 & 18.2 \\
\hline $\begin{array}{l}\text { Fricker et al. } \\
1988 \text { [247] }\end{array}$ & $\begin{array}{c}\text { Randomised } \\
\text { trial }\end{array}$ & 80 & $\begin{array}{l}\text { Patients with cancer } \\
\text { undergoing surgery for } \\
\text { abdominal and pelvic } \\
\text { malignancy }\end{array}$ & $\begin{array}{l}2500 \text { anti-Xa Units } \\
2 \mathrm{~h} \text { before surgery } \\
\text { and } 12 \mathrm{~h} \text { after the } \\
\text { first injection and } \\
\text { then } 5000 \text { anti-Xa } \\
\text { Units fragmin } \\
\text { injection q.d. } \times 10 \\
\text { days }\end{array}$ & $\begin{array}{l}5000 \text { IU of } \\
\text { calcium } \\
\text { heparin } \\
\text { injection } 2 \mathrm{~h} \\
\text { before the } \\
\text { surgery and } \\
\text { then t.i.d } \times \\
10 \text { days }\end{array}$ & 10 days & 5 & 5 \\
\hline $\begin{array}{l}\text { Godwin et al. } \\
1993 \text { [248] }\end{array}$ & $\begin{array}{l}\text { Double-blind } \\
\text { randomised trial }\end{array}$ & 904 & $\begin{array}{l}\text { Patients undergoing } \\
\text { abdominal or pelvic } \\
\text { cancer surgery }\end{array}$ & $\begin{array}{l}\text { RDH (Normiflo) } \\
50 \mathrm{U} 2 \mathrm{~h} \\
\text { preoperatively and } \\
\text { then } 90 \mathrm{U} \text { q.d./bd }\end{array}$ & $\begin{array}{l}\text { UFH } 5000 \mathrm{U} \\
2 \mathrm{~h} \text { preopera- } \\
\text { tively and } \\
\text { then } 5000 \mathrm{U} \\
\text { b.d. }\end{array}$ & & & \\
\hline $\begin{array}{l}\text { McLeod et al. } \\
2001 \text { [249] }\end{array}$ & $\begin{array}{c}\text { Randomise } \\
\text { double-blind } \\
\text { trial }\end{array}$ & 324 & $\begin{array}{l}\text { Patients with cancer } \\
\text { undergoing colorectal } \\
\text { cancer surgery }\end{array}$ & $\begin{array}{l}\text { Enoxaparin } 40 \mathrm{mg} \\
\text { q.d. } \times 10 \text { days }\end{array}$ & $\begin{array}{l}\text { Heparin } \\
5000 \text { U t.i.d. } \\
\times 10 \text { days }\end{array}$ & 10 days & 13.9 & 16.9 \\
\hline $\begin{array}{l}\text { Onarheim et al. } \\
1986 \text { [250] }\end{array}$ & $\begin{array}{l}\text { Randomised } \\
\text { double-blind } \\
\text { trial }\end{array}$ & 52 & $\begin{array}{l}\text { Patients undergoing } \\
\text { surgery for abdominal } \\
\text { malignancy }\end{array}$ & $\begin{array}{l}\text { Dalteparin } 5000 \mathrm{U} \\
2 \mathrm{~h} \text { preoperatively } \\
\text { then q.d. } \times 6 \text { days }\end{array}$ & $\begin{array}{c}\text { Heparin } \\
\text { Kabi2165 } \\
5000 \mathrm{U} 2 \mathrm{~h} \\
\text { preopera- } \\
\text { tively then } \\
\text { b.d. } \times 6 \text { days }\end{array}$ & 7 days & 1.92 & 3.84 \\
\hline
\end{tabular}

VTE: venous thromboembolism, LMWH: low molecular weight heparin, UFH: unfractionated heparin, sc: subcutaneous.

\section{Antitumor Effects of Anticoagulants}

A new perspective in the use of anticoagulant agents is that, in addition to preventing thromboembolic complications, these agents also improve survival rates in cancer patients by exerting antitumor effects. This theory has been supported by evidence from studies conducted with warfarin and LMWH [151-156]. This effect seems to be mediated by immunomodulatory actions, inhibition of angiogenesis, inhibition of release of coagulation proteases, and by triggering apoptosis [157].

\section{Mechanical Thromboprophylaxis}

Mechanical thromboprophylaxis is generally used as an adjunct to pharmacological therapy and includes modalities like electrical calf stimulation, intermittent pneumatic compression devices, graduated compression stockings (GCSs), and venous foot pump devices which increase venous outflow and/or reduce stasis within the leg veins [86]. Early and frequent ambulation of hospitalized patients at risk for VTE also helps to reduce venous stasis and is an important principle of postoperative patient care [86]. Unlike the 


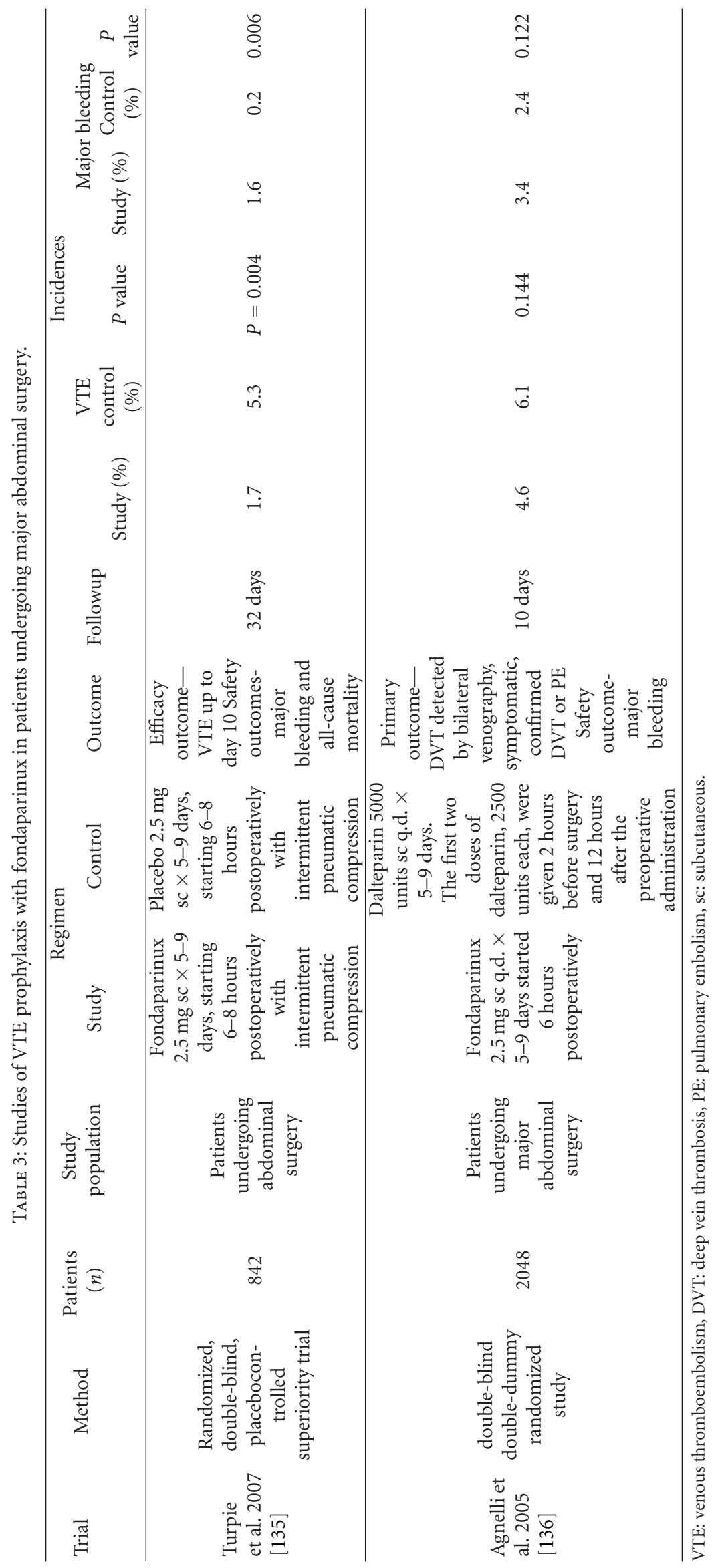


pharmacologic methods, the use of mechanical modalities does not increase the risk of bleeding, which makes it advantageous for use in patients who are at a high risk of bleeding, such as cancer patients [158-160]. When used in conjunction with the pharmacoprophylaxis, they have demonstrated an additive anticoagulant effect [161-168].

A meta-analysis published in 2001, which looked at 12 studies that had been conducted between 1992 and 1996, concluded that the use of graduated compression stockings alone for prophylaxis of VTE after moderate-risk surgery results in a significant risk reduction [169]. A review published in 2011 focused on the benefits of combination of modalities for prophylaxis [170]. Eleven studies were identified which evaluated combined intermittent pneumatic leg compression and pharmacological prophylaxis for prevention of VTE in high-risk patients, of which 6 studies were randomized controlled trials, and the study population in total was 7431 patients. They concluded that in comparison with compression alone, combined prophylactic modalities decrease the incidence of VTE significantly. Also, compared to pharmacological prophylaxis alone, combined modalities reduce the incidence of DVT significantly, but the effect on $\mathrm{PE}$ is unknown. Unfortunately, no large clinical trials specific to its use in cancer patients undergoing surgery have been published yet. Also the existing studies are few in number, have small sample size, with high potential for bias, and have failed to evaluate specific design features of each mechanical device $[132,171,172]$. Poor patient and staff compliance and high cost of purchase and maintenance of the device are other limitations to the use of mechanical prophylaxis [173177].

\section{Duration of Prophylaxis}

Traditionally, LMWH therapy was continued for a short period (1 week) following surgery in cancer patients. Later trials explored the efficacy and safety of extended (4 week) LMWH therapy in this group. The ENOXOCAN- and FAME-randomized control trials gave evidence for greater reduction in risk of VTE with extended prophylaxis, without a significant increase in the rate of bleeding or incidence of other complications [178, 179] (Table 4).

In the randomized, double-blind study CANBESURE, which enrolled patients admitted for abdominal or pelvic surgery for cancer, extended duration prophylaxis that was evaluated using bemiparin [180]. The primary efficacy outcome which was defined as the combined incidence at the end of double-blind period of total documented symptomatic and asymptomatic DVT, nonfatal PE and allcause mortality was not significantly reduced. But there was a decrease in major VTE, which was defined as the composite of symptomatic and asymptomatic proximal DVT, nonfatal PE and VTE-related deaths, without increasing hemorrhagic complications (Table 4).

However, in a retrospective study conducted between 2003 and 2006, to assess the occurrence of symptomatic VTE after major abdominal surgery for colorectal cancer in patients in whom LMWH was continued only until hospital discharge (median of 11 days), it was seen that among the 494 patients, only $3(0.6 \%)$ developed symptomatic VTE in the follow-up period, despite lack of extended prophylaxis [181]. The study concluded that postoperative LMWH for a median of 11 days, combined with the use of graded compression stockings, and early mobilization provided sufficient thromboprophylaxis.

Currently most guidelines recommend extended duration of prophylaxis with LMWH (up to 4 weeks postoperatively) in cancer patients who undergo major abdominal surgery [130, 131, 182, 183].

\section{Diagnosis}

Prompt and accurate diagnosis of DVT is crucial since proper anticoagulant treatment is necessary to reduce the risk of early and late complications. DVT can be suspected clinically based on signs and symptoms, and several clinical decision rules have been evaluated, of which "Wells decision rule" is the most widely tested and used clinical decision rule [184]. However, clinical diagnosis alone is insufficient because of poor sensitivity and specificity. Cogo et al. studied the role of compression ultrasound in patients with clinically suspected DVT and found that only one in four patients suspected of having DVT actually has the disease [185]. Therefore, an objective diagnosis is necessary to avoid the risk of denying treatment to patients in need or giving potentially harmful treatment to patients who do not need it [186].

\section{Clinical Decision Rules}

The Wells rule consists of nine items which can be obtained by medical history and physical examination [184]. On point is given for each item, and two points are deducted when an alternative diagnosis is considered more likely than DVT (Table 5). The decision rule initially divided patients into a low risk (0 points), an intermediate risk (1-2 points), and a high risk ( 3 or more points), However, it has been recently modified into two groups, namely, low probability ( $<2$ points) or high probability ( 2 or more points) of DVT [187]. The main drawback of the Wells rule is that it is not completely objective, due to the subjective element of considering an alternative diagnosis [188]. Current role of this clinical decision rule in the diagnosis of DVT is to guide further investigation.

\section{D-Dimer Testing}

D dimers generated by fibrinolysis of a thrombus has a molecular weight of 1,80,000 Daltons and its in vivo half life is 4 to 6 hours [189]. Several D-dimer assays are available with different sensitivities and specificities which recognize these $\mathrm{D}$ dimers by monoclonal antibodies. Assays with intermediate sensitivity and specificity are semi-quantitative latex (sensitivity $61-100 \%$, specificity $22-92 \%$ ), qualitative latex (sensitivity 77-87\%, specificity 100-100\%), and whole blood assay (sensitivity 53-100\%, specificity 20-94\%) [190]. Assays with high sensitivity and low specificity are enzyme-linked 


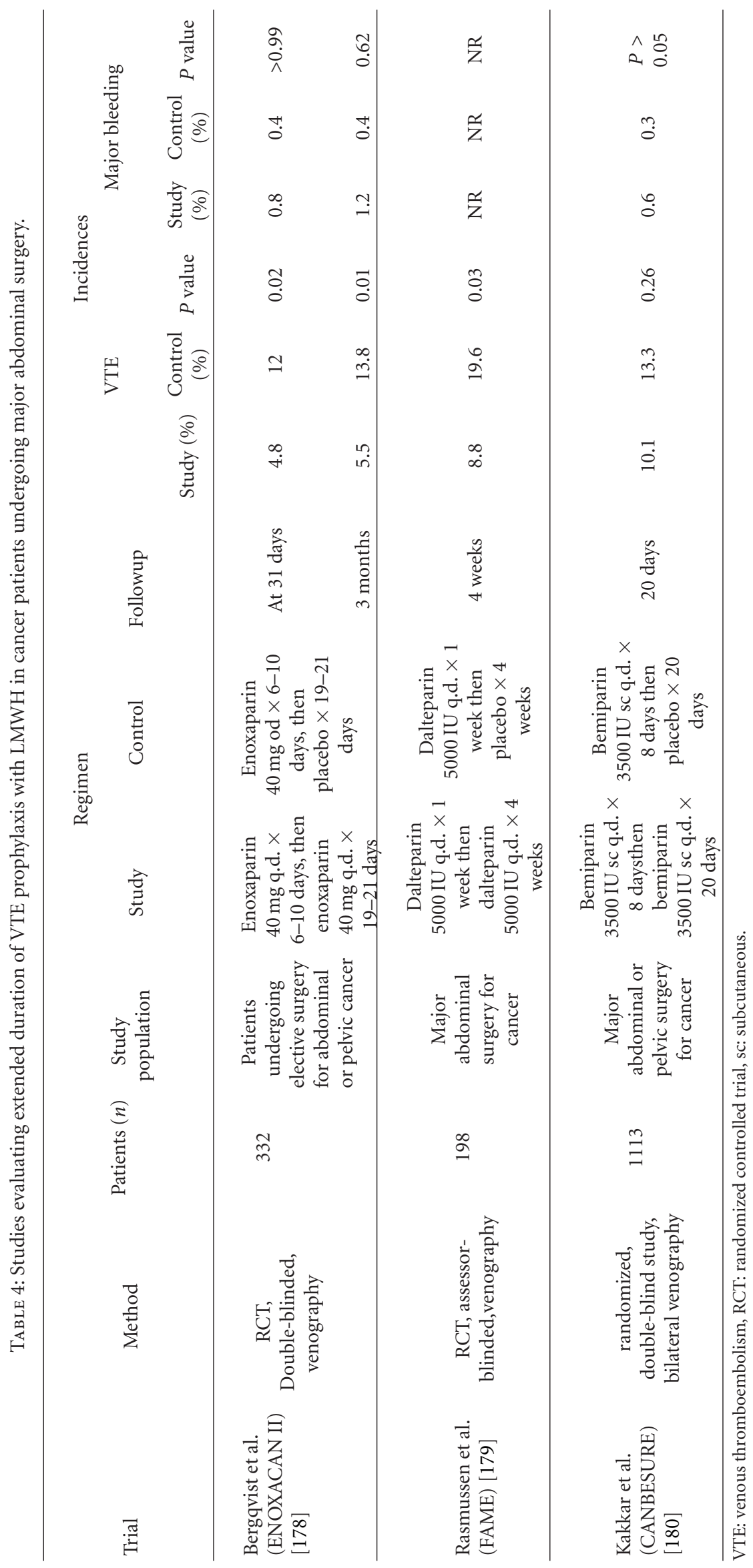


TABLE 5: Wells' prediction score for clinical diagnosis.

Clinical feature

Points

Active cancer (ongoing treatment or within last 6 months or palliative)

1

Paralysis, paresis, or recent plaster immobilization of lower extremities

Recently bedridden for $>3 \mathrm{~d}$ and/or major surgery within $12 \mathrm{wk}$ using regional or general anaesthesia

Local tenderness

Thigh and calf swollen

Calf swelling $3 \mathrm{~cm}>$ asymptomatic side (measured $10 \mathrm{~cm}$ below tibial tuberosity)

Pitting edema

Dilated superficial veins (nonvaricose) symptomatic leg only

Previous documented DVT

2 points deducted if alternative diagnosis is more likely than DVT.

Total points: $>2$ : DVT likely.

Total points: $<2$ : DVT unlikely.

immunosorbent assay (sensitivity $50-100 \%$, specificity $5-$ $82 \%$ ), enzyme-linked fluorescence assay (sensitivity 88 $100 \%$, specificity $5-82 \%$ ), and quantitative latex (sensitivity 57-100\%, specificity 26-97\%) [190]. Since D-dimer levels are increased in other conditions like infection, inflammation, cancer, surgery and trauma, extensive burns or bruises, ischemic heart disease, stroke, peripheral artery disease, ruptured aneurysm, aortic dissection, and pregnancy, it has low specificity in diagnosing DVT [191]. Since the main aim of D dimer testing is to rule out DVT, tests with high sensitivity are preferred for routine use.

\section{Imaging}

Both invasive (ascending venography or phlebography) and noninvasive modalities (ultrasonography, impedance plethysmography, computed tomography, and magnetic resonance imaging) are available for confirmation of diagnosis of DVT.

\section{Ascending Venography}

Ascending venography is still the gold standard for the diagnosis of DVT. Contrast medium is injected in a dorsal superficial vein of the foot, and serial radiograms are taken as the contrast medium flows cranially in the deep vein system. The diagnosis of DVT is confirmed with the finding of a constant intraluminal filling defect on two or more views. Treatment can be withheld safely when a technically adequate contrast venogram shows no evidence of DVT [192]. However, invasive nature of the technique, adverse reactions, and venous endothelial toxicity following contrast administration are well-known problems with ascending venography [193]. Furthermore, contrast venography is associated with a variation in interpretation in up to $10 \%$ of the cases and is relatively expensive [194]. Hence contrast venography is now seldom used for the diagnosis of DVT.

\section{Ultrasonography}

Ultrasonography (US) has become a widely accepted as a primary diagnostic procedure for the work-up of clinically suspected DVT. Initial attempts to diagnose DVT by visualization of a thrombus is associated with poor sensitivity since visibility of clot is dependent on the age of the clot. A fresh clot may appear almost anechoic and go unnoticed by visual inspection leading to under diagnosis [195]. Hence compression ultrasonography is commonly used in the radiological diagnosis of a first episode of clinically suspected DVT. In this technique, the femoral and popliteal veins are directly visualized and subsequently assessed for their compressibility in the transverse plane (two-point CUS). When a thrombus is present, compression of the vein is not possible even with a more firm pressure. This noncompressibility of the vein is established as a criterion for the diagnosis of DVT. Noncompressibility of either the femoral or popliteal vein, or both, is diagnostic for a first episode of acute proximal DVT in patients suspected of DVT with a sensitivity of $93.8 \%$ (95\% CI, $92-95.3 \%)$ and a specificity of $97.8 \%$ (95\% CI, 97-98.4\%) [196]. The interobserver agreement of CUS is excellent for proximal DVT of the leg [197]. Hence, currently CUS is first choice of imaging modality in the diagnostic workup of patients with a first episode of clinically suspected DVT of the lower extremities.

\section{Impedance Plethysmography}

Impedance plethysmography evaluates the efficiency of venous outflow by means of the electrical impedance variation of the lower limbs [198]. While it is noninvasive and easy to apply, it has two major limitations; impedance plethysmography cannot identify nonoccluding DVT, and therefore it is less useful in subjects with modest or absent clinical symptoms, since these patients frequently have nonoccluding DVT. Besides it is not useful in distal DVT and is limited to symptomatic subjects with proximal DVT [199]. With the advent of US impedance plethysmography is hardly used in the diagnosis of DVT.

\section{Computed Tomography (CT) and Magnetic Resonance Imaging (MRI)}

CT currently is used for the diagnosis of pulmonary embolism (PE) [200]. Given that DVT is the single most 
TABLE 6: Comparison of VTE pharmacoprophylactic recommendations laid down by ASCO, ACCP, NCCN, National Guideline Clearing House, and ESMO.

\begin{tabular}{|c|c|c|c|c|c|c|}
\hline & \multirow{2}{*}{$\begin{array}{l}\text { Guideline last } \\
\text { updated in }\end{array}$} & \multicolumn{4}{|c|}{ Drug } & \multirow{2}{*}{ Duration } \\
\hline & & Unfractionated heparin & Dalteparin & Enoxaparin & Fondaparinux & \\
\hline ASCO [127] & 2007 & $5,000 \mathrm{U}$ sc every 8 hours & 5,000 U sc daily & $40 \mathrm{mg}$ sc daily & $2.5 \mathrm{mg} s \mathrm{daily}$ & $\begin{array}{l}\text { Up to } 7-10 \text { days postop. } \\
\text { Up to } 4 \text { weeks post op in } \\
\text { high risk patients }\end{array}$ \\
\hline ACCP [129] & 2008 & $5,000 \mathrm{U}$ sc every 8 hours & 5,000 IU sc daily & 40 mg sc daily & $\begin{array}{l}\text { Not } \\
\text { recommended }\end{array}$ & $\begin{array}{l}\text { Up to } 4 \text { weeks after } \\
\text { discharge }\end{array}$ \\
\hline NCCN [205] & 2011 & $5,000 \mathrm{U}$ sc every 8 hours & 5,000 IU sc daily & 40 mg sc daily & $2.5 \mathrm{mg} s c$ daily & Up to 4 weeks postop \\
\hline ESMO [128] & 2011 & $5,000 \mathrm{U}$ sc every 8 hours & 5,000 U sc daily & 40 mg sc daily & $2.5 \mathrm{mg} \mathrm{sc}$ daily & $\begin{array}{l}\text { Up to discharge or until } \\
\text { ambulatory }\end{array}$ \\
\hline $\begin{array}{l}\text { National } \\
\text { Guideline } \\
\text { Clearinghouse } \\
\text { [204] }\end{array}$ & 2011 & $\begin{array}{c}5,000 \mathrm{U} \text { sc every } 12 \mathrm{hr} \\
\text { postop }\end{array}$ & $\begin{array}{l}\text { 2,500 units sc } \\
1-2 \mathrm{hr} \text { preop, } \\
\text { then every } 24 \mathrm{hr}\end{array}$ & $\begin{array}{l}40 \mathrm{mg} s \mathrm{c} 2 \mathrm{hr} \\
\text { preop, then } \\
\text { every } 24 \mathrm{hr}\end{array}$ & $\begin{array}{l}\text { Not } \\
\text { recommended }\end{array}$ & Up to 4 weeks postop \\
\hline
\end{tabular}

VTE: venous thromboembolism, ASCO: American Society for Oncology, ACCP: American College of Chest Physicians, NCCN: National Comprehensive Cancer Network, ESMO: European Society Of Medical Oncology; LMWH: low molecular weight heparin, sc: subcutaneously, postop: postoperatively.

important risk factor for PE, combining pulmonary CT and $\mathrm{CT}$ of the pelvic veins and lower limb veins improves sensitivity and specificity. In a recent meta-analysis, a pooled sensitivity for CT venography was $96 \%$ (95\% CI, 93-98\%) with a pooled specificity of $95 \%$ (95\% CI, 93.6-96.5\%) [201]. The disadvantages of CT are the high cost, difficulty when repeat scans are needed, the need to inject higher volumes of contrast medium when pulmonary angiography and venography are combined (with a higher risk of renal toxicity), and higher exposure to radiation especially to the ovaries or testicles in younger subjects.

MRI allows the visualization of proximal DVT with satisfactory accuracy, and it allows the diagnosis of the thrombotic extension into the iliac veins and the vena cava [202]. MRI is an alternative to venography in patients with an allergy to contrast medium or other contraindications to contrast media and/or renal insufficiency. The pooled sensitivity and specificity of MR-venography were reported to be $91.5 \%$ (95\% CI, 87.5-94.5\%) and 94.8\% (95\% CI, 92.6$96.5 \%)$, respectively [203].

Currently these techniques are recommended in patients with suspected DVT and in whom US cannot be performed or is less reliable, such as patients with morbid obesity, patients in casts and patients with a suspected DVT in the iliac veins or inferior vena cava.

\section{Guidelines for VTE Prophylaxis in Cancer Patients Undergoing Major Abdominal Surgery}

17.1. American Society for Clinical Oncology (ASCO). After extensive review of literature and clinical trials, the American society for Clinical Oncology laid down a set of guidelines in 2007 for VTE prophylaxis in cancer patients [127]. Pharmacologic prophylaxis with either low dose UFH or LMWH was recommended for all cancer patients undergoing major abdominal surgery. Thromboprophylaxis is relatively contraindicated in patients with active uncontrollable bleeding, active cerebrovascular hemorrhage, dissecting or cerebral aneurysm, bacterial endocarditis, pericarditis, active peptic or other GI ulceration, severe uncontrolled or malignant hypertension, severe head trauma, pregnancy (contraindication for use of warfarin), heparin-induced thrombocytopenia (contraindication for use of heparin, LMWH), and epidural catheter placement. The prophylaxis should be commenced preoperatively and continued for at least 7-10 days postoperatively. Patients with high-risk features such as residual malignant disease postoperatively, obesity, and previous history of VTE are candidates for prolonged postoperative prophylaxis (4 weeks) [127]. Details of pharmacoprophylaxis are outlined in Table 6.

17.2. European Society of Medical Oncology. The European Society of Medical Oncology brings out guidelines on VTE prophylaxis which are revised every year. The most recent supplement was brought out in 2011, and the recommendations are in keeping with those laid down by the ASCO [128]. Details of pharmacoprophylaxis are outlined in Table 6.

17.3. American College of Chest Physicians. The American College of Chest Physicians (ACCP) updated their recommendations regarding VTE prevention in patients undergoing surgery for cancer in 2008. Based on evidence from randomized controlled trials, in cancer patients undergoing general surgery, prophylaxis with low-dose UFH 5,000 U three times daily or with $\mathrm{LMWH}>3,400 \mathrm{U}$ daily (translates to 5,000 IU daily for dalteparin and $40 \mathrm{mg}$ daily for enoxaparin) is strongly recommended. Also postdischarge prophylaxis for patients who have undergone major cancer surgery is recommended [204]. Details of pharmacoprophylaxis are outlined in Table 6 .

17.4. National Guideline Clearing House. A Compendium of Consensus Recommendations from the American Academy of Chest Physicians (AACP), the American Society of 
Regional Anesthesia and Pain Medicine (ASRA) and American Academy of Orthopedic Surgery (AAOS) for the thromboembolic prophylaxis of adult hospitalized patients were chartered under the National Guideline Clearing house in 2010 in association with the Institute for Clinical Systems Improvement (ICSI). The updated eighth edition was released in September 2011. It differed from the ASCO guidelines in not recommending the use of fondaparinux [204]. Details of pharmacoprophylaxis are outlined in Table 6.

17.5. National Comprehensive Cancer Network. The National Comprehensive Cancer Network (NCCN) guidelines are a statement of consensus of its authors with respect to their views of currently accepted approaches to prophylaxis and treatment of VTE in adult cancer inpatient with a diagnosis of (or clinical suspicion for) cancer. It differs from other guidelines in permitting use of tinzaparin for pharmacoprophylaxis [205]. Details of pharmacoprophylaxis are outlined in Table 6 .

17.6. Guidelines on Mechanical Prophylaxis. The commonly employed mechanical methods of thromboprophylaxis include graduated compression stockings (GCSs), intermittent pneumatic compression (IPC) devices, the venous foot pumps (VFPs), and Inferior Vena cava filters. The ASCO, ESMO, AACP and NCCN guidelines state that mechanical methods may be used in conjunction with the pharmacologic methods in high-risk patients (patients with recurrent pulmonary embolism) despite adequate anticoagulant treatment or with a contraindication to anticoagulant therapy (i.e., active bleeding and profound, prolonged thrombocytopenia), and are recommended as monotherapy only in cases where pharmacologic measures are contraindicated due to high risk of active bleeding [127-129, 204, 205]. Once the risk decreases the ACCP recommend that the mechanical method be substituted/supplemented by a pharmacologic agent [129]. The ACCP guideline further recommends that patients receiving these methods be subjected to careful attention to ensure proper use and to maintain their compliance with these methods [129].

\section{Treatment of VTE in Cancer Patients}

The chief objectives of treatment are to prevent the extension of DVT, the occurrence of pulmonary embolism, recurrence of VTE, and to prevent long-term VTE and PE complications such as postthrombotic syndrome and chronic thromboembolic pulmonary hypertension.

When compared to general medical patients, treatment of VTE in cancer patients is more challenging due to the higher frequency of recurrence and bleeding complications (despite appropriate anticoagulation and well-maintained International Normalized Ratio (INR) ) [7, 10, 206-209]. The conventional protocol of treatment has been 5-7 days of therapeutic dose of UFH, followed by long-term treatment with Vitamin K antagonists (VKA) for a minimum of 3 months, titrated to an INR of 2.0-3.0 [91, 210]. But the limitations of warfarin and UFH use, as described in the previous section, have shifted focus on LMWH as the chief modality of treatment. Comparison of different LMWH such as dalteparin, enoxaparin, and tinzaparin with warfarin, and UFH has been carried out in trials which have significantly demonstrated superior efficacy and safety profiles of LMWH for treatment of VTE in cancer patients and hence guidelines currently recommended LMWH for initial and long term treatment of acute VTE in cancer patients [127-129, 204, 205].

Trials have also been conducted to evaluate the role of direct thrombin inhibitors such ximelagatran and factor Xa inhibitors like fondaparinux in VTE treatment $[211,212]$. In the THRIVE study on 2489 patients ( $13 \%$ of whom had cancer), it was reported that oral fixed dose ximelgatran was as effective as enoxaparin/warfarin for treatment of DVT with or without PE and showed similar rates of bleeding though other systemic side effects observed with ximelgatran are a cause for concern [211]. Post hoc analyses of the MatisseDVT and Matisse-PE trials aimed to compare efficacy and overall survival of fondaparinux with LMWH and UFH in the initial treatment of 237 cancer patients with DVT and 240 cancer patients with PE, respectively [212]. In the DVT subgroup analysis, results showed a trend towards higher rates of recurrent VTE in fondaparinux-treated patients than enoxaparin-treated patients ( $12.7 \%$ versus $5.4 \% ; P=0.046)$ [212]. In the PE subgroup analysis, results showed higher rates of recurrent VTE in the UFH group when compared with the fondaparinux group $(17.2 \%$ versus $8.9 \%, P=$ $0.054)$ [212]. In both analyses, no difference in bleeding and overall survival was observed.

\section{Guidelines for VTE Treatment in Cancer Patients}

The recommendations made by ASCO, NCCN, and ESMO guidelines for initial and long-term treatment of VTE in patients with cancer are listed in Table 7.

Recurrent VTE in a cancer patient despite adequate anticoagulation might be indicative of progression of the malignancy. For treatment of such patients, the options include shift to treatment with LMWH/UFH (if previously on long-term treatment with VKA), increase target INR to 3.5 , or consider the use of inferior vena cava filter if recurrent PE despite adequate long-term LMWH [213]. The option of increasing the dose of LMWH in cancer patients with recurrent VTE has also been recently explored [214].

\section{Evaluation of Use of Venous Thromboembolism Prophylaxis in Clinical Practice}

The higher likelihood of development of VTE in surgical oncology patients has been well enumerated, and the benefit offered by prophylactic measures has been documented. Also a large number of evidence-based clinical guidelines and expert recommendations have been laid down in this context. Yet an underuse of these preventive measures 


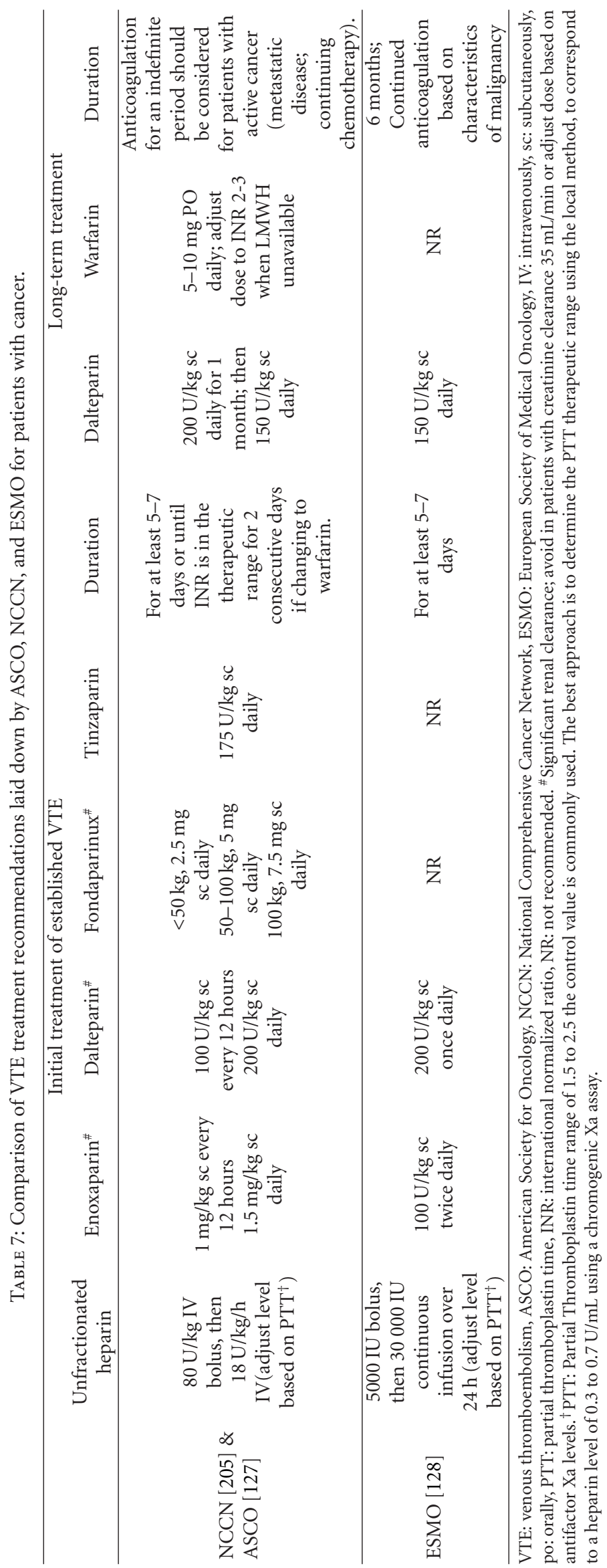


persists, as evident from the results of some recent studies [215-219].

In a retrospective medical record review conducted in 2000 , among the 495 patients ( $71.3 \%$ of whom had cancer) who had undergone major abdominal surgery, only $25.4 \%$ had received prophylaxis which conformed to the 1995ACCP criteria [218]. In the global Fundamental Research in Oncology and Thrombosis (FRONTLINE) study of 2001, conducted by distributing questionnaires to clinicians involved in cancer care, the knowledge and practice of VTE prophylaxis was reviewed for 3891 clinicians worldwide. Analysis showed that only $52 \%$ of the respondents routinely prescribed thromboprophylactic measures for cancer patients undergoing surgery [219]. Also of concern is the continued use of aspirin as a prophylactic agent by almost $20 \%$ of the physicians, despite the lack of supporting evidence to do so [219]. A large scale survey was conducted in the Unites States between 2003 and 2007 where in data on VTE prophylactic practices in oncologic patients undergoing surgery was collected using the Perspective database in an attempt to identify factors which influence the variability in the same. The data published in 2011 showed that, in a total of 252,950 patients, $79 \%$ received some form of prophylaxis, and in $46 \%$ of patients this was pharmacologic. Also it was noted that rates of prophylaxis were significantly higher in high volume hospitals and patients under therapy with high volume surgeons [220].

Also of concern is the lack of extended prophylaxis in practice, despite evidence from trials and guidelines which reaffirm its benefit. In a prospective study (ESSENTIAL) conducted at 14 Swiss hospitals, of the 1046 cancer patients included in the study, $30 \%$ underwent major cancer surgery. More than $95 \%$ of them received appropriate in hospital prophylaxis, but only $23 \%$ were given prescriptions for extended pharmacological prophylaxis at discharge. Also the median duration of prescription among those who received it was 23 days, lower than the recommended 28 days [221].

20.1. Reasons for Poor Implementation of Guidelines. Most of the barriers to effective and comprehensive implementation of prophylactic measures are attributed to physician-related factors [222]. There is a lack of awareness among physicians about the extent of risk of VTE involved in such patients and of the currently recommended management strategies [223]. Lack of familiarity and in some cases, agreement with the recommendations issued in the guidelines, along with the lack of confidence and motivation to alter existing practice patterns are common hindering factors [224]. Also certain erroneous notions like "increased risk of bleeding occurs with anticoagulant therapy in patients with cancer due to underlying procoagulant milieu created by the malignant state" are still fostered by physicians, despite evidence from studies proving good safety profile of LMWH and UFH [225-232]. Additionally the presence of multiple guidelines with varied protocols makes it confusing and complicated for physicians to follow [224]. The need for official approval and funding for the recommended drugs adds to the inconvenience faced by physicians and hence leads to the underuse of prophylaxis [224].
20.2. Improving the Implementation of Guidelines. To tackle these hurdles in implementation and bring about increased thrombopropylaxis rates and better outcomes for patients, quality improvement strategies [233, 234] have been proposed and employed such as the following.

20.2.1. Continuing Medical Education. Conducting workshops/presentations for health care providers, nurses, and pharmacists to stress on the importance of prophylaxis and to update their understanding of it has been shown to improve thromboprophylaxis rates and reduce the prevalence of VTE [162, 235-238]. By engaging recognized opinion leaders in the process of knowledge dissemination, physician practicing habits may be significantly influenced and changed [239-241].

20.2.2. Clinical Audits and Feedback. Active forms of interventions such as conducting audits and providing feedback have been shown to have the potential to alter physician's practice, improve their adherence to guidelines, and have an upper hand compared to passive techniques like educational mailings $[239,240]$. In a UK study, the adherence to hospital policy on use of compression stockings and heparin in orthopedic joint replacement surgery patients was evaluated twice, three months apart, with feedback being provided to health care providers after the initial assessment. Comparison of quality of implementation of hospital protocol evaluated on both occasions revealed an improvement following the feedback session [242].

20.2.3. Clinical-Decision Support Tools. Computer-based reminders/alerts have shown great potential in making prescription of VTE prophylaxis measures more convenient, accurate, and frequent and thus reducing the incidence of VTE in hospitalized patients who are at risk for thrombosis [243]. An alternative option of using preprinted prophylaxis reminders/risk assessment models/guidelines on drug charts/hospital admission forms has also shown improvement in the use of anticoagulants in practice $[236,244]$.

20.2.4. Role of Supervising Organizations. Quality improvement organizations such as the National Quality Forum, the Surgical Care Improvement Project, the Agency for Healthcare Research and Quality, and the Joint Commission play a major role in bridging the gap between clinical guidelines and their implementation. Multipronged programs have to be planned and initiated to improve VTE prophylaxis rates. Also simplified guidelines such as the pocket guide developed by Investigators against Thromboembolism (INATE) initiative for orthopedic and trauma surgery serve to resolve inconsistencies between guidelines and present them in a more convenient format [245]. No individual quality improvement strategy method has proven to be singularly exceptional in its effectiveness, and studies show that an integration of several techniques yields best results [162, 236-238]. 


\section{References}

[1] A. Trousseau, "Phlegmasia alba dolens," Clinique Médicale de l'Hôtel-Dieu de Paris, 3. Paris: Ballière, pp. 654-712, 1865.

[2] J. A. Heit, M. D. Silverstein, D. N. Mohr, T. M. Petterson, W. M. O'Fallon, and L. J. Melton II, "Risk factors for deep vein thrombosis and pulmonary embolism: a population-based case-control study," Archives of Internal Medicine, vol. 160, no. 6, pp. 809-815, 2000.

[3] M. D. Silverstein, J. A. Heit, D. N. Mohr, T. M. Petterson, W. M. O'Fallon, and L. J. Melton, "Trends in the incidence of deep vein thrombosis and pulmonary embolism: a 25-year population-based study," Archives of Internal Medicine, vol. 158, no. 6, pp. 585-593, 1998.

[4] J. A. Heit, W. Michael O'Fallon, T. M. Petterson et al., "Relative impact of risk factors for deep vein thrombosis and pulmonary embolism: a population-based study," Archives of Internal Medicine, vol. 162, no. 11, pp. 1245-1248, 2002.

[5] J. W. Blom, C. J. M. Doggen, S. Osanto, and F. R. Rosendaal, "Malignancies, prothrombotic mutations, and the risk of venous thrombosis," Journal of the American Medical Association, vol. 293, no. 6, pp. 715-722, 2005.

[6] A. K. Kakkar and R. C. N. Williamson, "Prevention of venous thromboembolism in cancer patients," Seminars in Thrombosis and Hemostasis, vol. 25, pp. 239-243, 1999.

[7] B. A. Hutten, M. H. Prins, M. Gent, J. Ginsberg, J. G. P. Tijssen, and H. R. Buller, "Incidence of recurrent thromboembolic and bleeding complications among patients with venous thromboembolism in relation to both malignancy and achieved International Normalized Ratio: a retrospective analysis," Journal of Clinical Oncology, vol. 18, no. 17, pp. 3078-3083, 2000.

[8] P. Prandoni, A. W. A. Lensing, A. Piccioli et al., "Recurrent venous thromboembolism and bleeding complications during anticoagulant treatment in patients with cancer and venous thrombosis," Blood, vol. 100, no. 10, pp. 3484-3488, 2002.

[9] G. Agnelli, G. Bolis, L. Capussotti et al., "A clinical outcomebased prospective study on venous thromboembolism after cancer surgery: the @RISTOS Project," Annals of Surgery, vol. 243, no. 1, pp. 89-95, 2006.

[10] N. Levitan, A. Dowlati, S. C. Remick et al., "Rates of initial and recurrent thromboembolic disease among patients with malignancy versus those without malignancy: risk analysis using medicare claims data," Medicine, vol. 78, no. 5, pp. 285291, 1999.

[11] H. T. Sørensen, L. Mellemkjær, J. H. Olsen, and J. A. Baron, "Prognosis of cancers associated with venous thromboembolism," The New England Journal of Medicine, vol. 343, no. 25, pp. 1846-1850, 2000.

[12] M. H. Prins, R. J. K. Hettiarachchi, A. W. A. Lensing, and J. Hirsh, "Newly diagnosed malignancy in patients with venous thromboembolism. Search or wait and see?" Thrombosis and Haemostasis, vol. 78, no. 1, pp. 121-125, 1997.

[13] J. A. Baron, G. Gridley, E. Weiderpass, O. Nyrén, and M. Linet, "Venous thromboembolism and cancer," The Lancet, vol. 351, no. 9109, pp. 1077-1080, 1998.

[14] H. T. Sørensen, L. Mellemkjær, F. H. Steffensen, J. H. Olsen, and G. L. Nielsen, "The risk of a diagnosis of cancer after primary deep venous thrombosis or pulmonary embolism," The New England Journal of Medicine, vol. 338, no. 17, pp. 1169-1173, 1998.

[15] G. Palareti, C. Legnani, A. Lee et al., "A comparison of the safety and efficacy of oral anticoagulation for the treatment of venous thromboembolic disease in patients with or without malignancy," Journal of Thrombosis and Haemostasis, vol. 84, pp. 805-810, 2000.

[16] P. D. Stein, A. Beemath, F. A. Meyers, E. Skaf, J. Sanchez, and R. E. Olson, "Incidence of venous thromboembolism in patients hospitalized with cancer," American Journal of Medicine, vol. 119, no. 1, pp. 60-68, 2006.

[17] A. A. Khorana, C. W. Francis, E. Culakova, N. M. Kuderer, and G. H. Lyman, "Frequency, risk factors, and trends for venous thromboembolism among hospitalized cancer patients," Cancer, vol. 110, no. 10, pp. 2339-2346, 2007.

[18] G. Grignani and A. Maiolo, "Cytokines and hemostasis," Haematologica, vol. 85, no. 9, pp. 967-972, 2000.

[19] A. A. Khorana, S. A. Ahrendt, C. K. Ryan et al., "Tissue factor expression, angiogenesis, and thrombosis in pancreatic cancer," Clinical Cancer Research, vol. 13, no. 10, pp. 2870-2875, 2007.

[20] A. K. Kakkar, N. R. Lemoine, M. F. Scully, S. Tebbutt, and R. C. N. Williamson, "Tissue factor expression correlates with histological grade in human pancreatic cancer," British Journal of Surgery, vol. 82, no. 8, pp. 1101-1104, 1995.

[21] J. I. Zwicker, "Tissue factor-bearing microparticles and cancer," Seminars in Thrombosis and Hemostasis, vol. 34, pp. 195198, 2008.

[22] J. F. Bazan, "Structural design and molecular evolution of a cytokine receptor superfamily," Proceedings of the National Academy of Sciences of the United States of America, vol. 87, no. 18, pp. 6934-6938, 1990.

[23] H. F. Dvorak, S. C. Quay, and N. S. Orenstein, "Tumor shedding and coagulation," Science, vol. 212, no. 4497, pp. 923-924, 1981.

[24] T. Nakasaki, H. Wada, C. Shigemori et al., "Expression of tissue factor and vascular endothelial growth factor is associated with angiogenesis in colorectal cancer," American Journal of Hematology, vol. 69, no. 4, pp. 247-254, 2002.

[25] M. E. T. Tesselaar, F. P. H. T. M. Romijn, I. K. Van Der Linden, F. A. Prins, R. M. Bertina, and S. Osanto, "Microparticleassociated tissue factor activity: a link between cancer and thrombosis?" Journal of Thrombosis and Haemostasis, vol. 5, no. 3, pp. 520-527, 2007.

[26] K. Uno, S. Homma, T. Satoh et al., "Tissue factor expression as a possible determinant of thromboembolism in ovarian cancer," British Journal of Cancer, vol. 96, no. 2, pp. 290-295, 2007.

[27] A. A. Khorana, C. W. Francis, K. E. Menzies et al., "Plasma tissue factor may be predictive of venous thromboembolism in pancreatic cancer," Journal of Thrombosis and Haemostasis, vol. 6, no. 11, pp. 1983-1985, 2008.

[28] F. R. Rickles and A. Falanga, "Molecular basis for the relationship between thrombosis and cancer," Thrombosis Research, vol. 102, no. 6, pp. V215-V224, 2001.

[29] T. C. Haddad and E. W. Greeno, "Chemotherapy-induced thrombosis," Thrombosis Research, vol. 118, no. 5, pp. 555$568,2006$.

[30] A. Y. Lee, "Cancer and thromboembolic disease: pathogenic mechanisms," Cancer Treatment Reviews, vol. 28, no. 3, pp. 137-140, 2002.

[31] F. R. Rickles, G. A. Hair, R. A. Zeff, E. Lee, and R. D. Bona, "Tissue factor expression in human leukocytes and tumor cells," Thrombosis and Haemostasis, vol. 74, no. 1, pp. 391395, 1995.

[32] M. Wahrenbrock, L. Borsig, D. Le, N. Varki, and A. Varki, "Selectin-mucin interactions as a probable molecular explanation for the association of Trousseau syndrome with 
mucinous adenocarcinomas," Journal of Clinical Investigation, vol. 112, no. 6, pp. 853-862, 2003.

[33] I. Gouin-Thibault and M. M. Samama, "Laboratory diagnosis of the thrombophilic state in cancer patients," Seminars in Thrombosis and Hemostasis, vol. 25, pp. 167-172, 1999.

[34] A. Falanga and F. R. Rickles, "Pathophysiology of the thrombophilic state in the cancer patient," Seminars in Thrombosis and Hemostasis, vol. 25, pp. 173-182, 1999.

[35] S. A. Mousa, "Anticoagulants in thrombosis and cancer: the missing link," Seminars in Thrombosis and Hemostasis, vol. 28, pp. 45-52, 2002.

[36] M. P. Bevilacqua, J. S. Pober, G. R. Majeau, W. Fiers, R. S. Cotran, and M. A. Gimbrone Jr., "Recombinant tumor necrosis factor induces procoagulant activity in cultured human vascular endothelium: characterization and comparison with the actions of interleukin 1," Proceedings of the National Academy of Sciences of the United States of America, vol. 83, pp. 4533-4537, 1986.

[37] S. R. Deitcher, "Cancer and thrombosis: mechanisms and treatment," Journal of Thrombosis and Thrombolysis, vol. 16, no. 1-2, pp. 21-31, 2003.

[38] I. C. Weitz, V. K. Israel, J. R. Waisman, C. A. Presant, L. Rochanda, and H. A. Liebman, "Chemotherapy-induced activation of hemostasis: effect of a low molecular weight heparin (dalteparin sodium) on plasma markers of hemostatic activation," Thrombosis and Haemostasis, vol. 88, no. 2, pp. 213-220, 2002.

[39] B. C. Kuenen, M. Levi, J. C. M. Meijers et al., "Analysis of coagulation cascade and endothelial cell activation during inhibition of vascular endothelial growth factor/vascular endothelial growth factor receptor pathway in cancer patients," Arteriosclerosis, Thrombosis, and Vascular Biology, vol. 22, no. 9, pp. 1500-1505, 2002.

[40] M. Cwikiel, J. Eskilsson, M. Albertsson, and L. Stavenow, "The influence of 5-fluorouracil and methotrexate on vascular endothelium. An experimental study using endothelial cells in the culture," Annals of Oncology, vol. 7, no. 7, pp. 731737, 1996.

[41] G. I. Togna, A. R. Togna, M. Franconi, and L. Caprino, "Cisplatin triggers platelet activation," Thrombosis Research, vol. 99, no. 5, pp. 503-509, 2000.

[42] N. Paredes, L. Xu, L. R. Berry, and A. K. C. Chan, "The effects of chemotherapeutic agents on the regulation of thrombin on cell surfaces," British Journal of Haematology, vol. 120, no. 2, pp. 315-324, 2003.

[43] J. S. Rogers II, A. J. Murgo, J. A. Fontana, and P. C. Raich, "Chemotherapy for breast cancer decreases plasma protein C and protein S," Journal of Clinical Oncology, vol. 6, no. 2, pp. 276-281, 1988.

[44] J. Woodley-Cook, L. Y. Y. Shin, L. Swystun, S. Caruso, S. Beaudin, and P. C. Liaw, "Effects of the chemotherapeutic agent doxorubicin on the protein $\mathrm{C}$ anticoagulant pathway," Molecular Cancer Therapeutics, vol. 5, no. 12, pp. 3303-3311, 2006.

[45] A. A. Khorana, H. A. Liebman, and R. H. White, The Risk of Venous Thromboembolism in Patients with Cancer, ASCO Educational Book, American Society of Clinical Oncology, Alexandria, Va, USA, 2008.

[46] A. A. Khorana, C. W. Francis, E. Culakova, R. I. Fisher, N. M. Kuderer, and G. H. Lyman, "Thromboembolism in hospitalized neutropenic cancer patients," Journal of Clinical Oncology, vol. 24, no. 3, pp. 484-490, 2006.

[47] M. Margaglione, V. Brancaccio, D. De Lucia et al., "Inherited thrombophilic risk factors and venous thromboembolism: distinct role in peripheral deep venous thrombosis and pulmonary embolism," Chest, vol. 118, no. 5, pp. 1405-1411, 2000.

[48] J. W. Blom, J. P. M. Vanderschoot, M. J. Oostindiër, S. Osanto, F. J. M. Van Der Meer, and F. R. Rosendaal, "Incidence of venous thrombosis in a large cohort of 66329 cancer patients: results of a record linkage study," Journal of Thrombosis and Haemostasis, vol. 4, no. 3, pp. 529-535, 2006.

[49] P. A. Thodiyil and A. K. Kakkar, "Variation in relative risk of venous thromboembolism in different cancers," Thrombosis and Haemostasis, vol. 87, no. 6, pp. 1076-1077, 2002.

[50] S. Sallah, J. Y. Wan, and N. P. Nguyen, "Venous thrombosis in patients with solid tumors: determination of frequency and characteristics," Thrombosis and Haemostasis, vol. 87, no. 4, pp. 575-579, 2002.

[51] A. Alcalay, T. Wun, V. Khatri et al., "Venous thromboembolism in patients with colorectal cancer: incidence and effect on survival," Journal of Clinical Oncology, vol. 24, no. 7, pp. 1112-1118, 2006.

[52] H. K. Chew, T. Wun, D. Harvey, H. Zhou, and R. H. White, "Incidence of venous thromboembolism and its effect on survival among patients with common cancers," Archives of Internal Medicine, vol. 166, no. 4, pp. 458-464, 2006.

[53] P. D. Stein, S. E. Fowler, L. R. Goodman et al., "Multidetector computed tomography for acute pulmonary embolism," The New England Journal of Medicine, vol. 354, no. 22, pp. 23172327, 2006

[54] A. C. Spyropoulos, D. J. Brotman, A. N. Amin, S. B. Deitelzweig, A. K. Jaffer, and S. C. McKean, "Prevention of venous thromboembolism in the cancer surgery patient," Cleveland Clinic journal of medicine, vol. 75, pp. S17-S26, 2008.

[55] K. Kröger, D. Weiland, C. Ose et al., "Risk factors for venous thromboembolic events in cancer patients," Annals of Oncology, vol. 17, no. 2, pp. 297-303, 2006.

[56] A. A. Khorana, C. W. Francis, E. Culakova, and G. H. Lyman, "Risk factors for chemotherapy-associated venous thromboembolism in a prospective observational study," Cancer, vol. 104, no. 12, pp. 2822-2829, 2005.

[57] C. Fotopoulou, A. Dubois, A. N. Karavas et al., "Incidence of venous thromboembolism in patients with ovarian cancer undergoing platinum/paclitaxel-containing first-line chemotherapy: an exploratory analysis by the Arbeitsgemeinschaft Gynaekologische Onkologie Ovarian Cancer Study Group," Journal of Clinical Oncology, vol. 26, no. 16, pp. 2683-2689, 2008.

[58] R. Alikhan, A. T. Cohen, S. Combe et al., "MEDENOX Study. Risk factors for venous thromboembolism in hospitalized patients with acute medical illness: analysis of the MEDENOX Study," Archives of Internal Medicine, vol. 164, no. 9, pp. 963-968, 2004.

[59] M. Kennedy, A. C. M. Andreescu, M. S. Greenblatt et al., "Factor V Leiden, prothrombin 20210A and the risk of venous thrombosis among cancer patients," British Journal of Haematology, vol. 128, no. 3, pp. 386-388, 2005.

[60] A. Eroglu, A. Ulu, R. Çam, C. Kurtman, and N. Akar, "Prevalence of factor V $1691 \mathrm{G}-\mathrm{A}$ (Leiden) and prothrombin G20210A polymorphisms and the risk of venous thrombosis among cancer patients," Journal of Thrombosis and Thrombolysis, vol. 23, no. 1, pp. 31-34, 2007.

[61] A. Y. Y. Lee and M. N. Levine, "The thrombophilic state induced by therapeutic agents in the cancer patient," Seminars in Thrombosis and Hemostasis, vol. 25, pp. 137-145, 1999. 
[62] M. Mandalà, A. Falanga, and F. Roila, "ESMO Guidelines Working Group. Venous thromboembolism in cancer patients: ESMO Clinical Practice Guidelines for the management," Annals of Oncology, vol. 21, pp. v274-v276, 2010.

[63] T. Saphner, D. C. Tormey, and R. Gray, "Venous and arterial thrombosis in patients who received adjuvant therapy for breast cancer," Journal of Clinical Oncology, vol. 9, no. 2, pp. 286-294, 1991.

[64] B. Fisher, J. P. Costantino, D. L. Wickerham et al., "Tamoxifen for prevention of breast cancer: report of the National Surgical Adjuvant Breast and Bowel Project P-1 study," Journal of the National Cancer Institute, vol. 90, no. 18, pp. 1371-1388, 1998.

[65] K. I. Pritchard, A. H. Paterson, N. A. Paul, B. Zee, S. Fine, and J. Pater, "Increased thromboembolic complications with concurrent tamoxifen and chemotherapy in a randomized trial of adjuvant therapy for women with breast cancer. National Cancer Institute of Canada Clinical Trials Group Breast Cancer Site Group," Journal of Clinical Oncology, vol. 14, pp. 2731-2737, 1996.

[66] F. Kabbinavar, H. I. Hurwitz, L. Fehrenbacher et al., "Phase II, randomized trial comparing bevacizumab plus fluorouracil (FU)/leucovorin (LV) with FU/LV alone in patients with metastatic colorectal cancer," Journal of Clinical Oncology, vol. 21, no. 1, pp. 60-65, 2003.

[67] S. V. Rajkumar, E. Blood, D. Vesole, R. Fonseca, and P. R. Greipp, "Phase III clinical trial of thalidomide plus dexamethasone compared with dexamethasone alone in newly diagnosed multiple myeloma: a clinical trial coordinated by the eastern cooperative oncology group," Journal of Clinical Oncology, vol. 24, no. 3, pp. 431-436, 2006.

[68] M. Zangari, E. Anaissie, B. Barlogie et al., "Increased risk of deep-vein thrombosis in patients with multiple myeloma receiving thalidomide and chemotherapy," Blood, vol. 98, no. 5, pp. 1614-1615, 2001.

[69] C. L. Bennett, C. Angelotta, P. R. Yarnold et al., "Thalidomide- and lenalidomide-associated thromboembolism among patients with cancer," Journal of the American Medical Association, vol. 296, no. 21, pp. 2558-2560, 2006.

[70] H. Hurwitz, L. Fehrenbacher, W. Novotny et al., "Bevacizumab plus irinotecan, fluorouracil, and leucovorin for metastatic colorectal cancer," The New England Journal of Medicine, vol. 350, no. 23, pp. 2335-2342, 2004.

[71] S. V. Rajkumar, "Thalidomide therapy and deep venous thrombosis in multiple myeloma," Mayo Clinic Proceedings, vol. 80, no. 12, pp. 1549-1551, 2005.

[72] S. V. Rajkumar and M. A. Gertz, "Lenalidomide therapy and deep-vein thrombosis in multiple myeloma," Blood, vol. 108, no. 1, p. 404, 2006.

[73] R. Knight, R. J. DeLap, and J. B. Zeldis, "Lenalidomide and venous thrombosis in multiple myeloma," The New England Journal of Medicine, vol. 354, no. 19, pp. 2079-2080, 2006.

[74] J. Bohlius, J. Wilson, J. Seidenfeld et al., "Recombinant human erythropoietins and cancer patients: updated metaanalysis of 57 studies including 9353 patients," Journal of the National Cancer Institute, vol. 98, no. 10, pp. 708-714, 2006.

[75] D. Bergqvist, "Risk of venous thromboembolism in patients undergoing cancer surgery and options for thromboprophylaxis," Journal of Surgical Oncology, vol. 95, no. 2, pp. 167174, 2007.

[76] A. Y. Y. Lee, M. N. Levine, G. Butler et al., "Incidence, risk factors, and outcomes of catheter-related thrombosis in adult patients with cancer," Journal of Clinical Oncology, vol. 24, no. 9, pp. 1404-1408, 2006.

[77] M. E. T. Tesselaar, J. Ouwerkerk, M. A. Nooy, F. R. Rosendaal, and S. Osanto, "Risk factors for catheter-related thrombosis in cancer patients," European Journal of Cancer, vol. 40, no. 15, pp. 2253-2259, 2004.

[78] A. Cortelezzi, M. Moia, and A. Falanga, "Incidence of thrombotic complications in patients with haematological malignancies with central venous catheters: a prospective multicentre study," British Journal of Haematology, vol. 129, pp. 811-817, 2005.

[79] S. Couban, D. R. Simpson, M. J. Barnett et al., "A randomized multicenter comparison of bone marrow and peripheral blood in recipients of matched sibling allogeneic transplants for myeloid malignancies," Blood, vol. 100, no. 5, pp. 15251531, 2002.

[80] L. J. Walshe, S. F. Malak, J. Eagan, and K. A. Sepkowitz, "Complication rates among cancer patients with peripherally inserted central catheters," Journal of Clinical Oncology, vol. 20, no. 15, pp. 3276-3281, 2002.

[81] N. Kucher, S. Koo, R. Quiroz et al., "Electronic alerts to prevent venous thromboembolism among hospitalized patients," The New England Journal of Medicine, vol. 352, no. 10, pp. 969-977, 2005.

[82] A. Khorana, N. M. Kuderer, E. Culakova, G. H. Lyman, and C. W. Francis, "Development and validation of a predictive model for chemotherapy- associated thrombosis," Blood, vol. 111, no. 10, pp. 4902-4907, 2008.

[83] J. A. Heit, D. N. Mohr, M. D. Silverstein, T. M. Petterson, W. M. O'Fallon, and L. J. Melton, "Predictors of recurrence after deep vein thrombosis and pulmonary embolism: a population-based cohort study," Archives of Internal Medicine, vol. 160, no. 6, pp. 761-768, 2000.

[84] D. Reeves and C. Y. Liu, "Retrospective evaluation of venous thromboembolism prophylaxis in the adult cancer population," Journal of Oncology Pharmacy Practice, vol. 16, pp. 2731, 2010.

[85] P. O. Hansson, J. Sörbo, and H. Eriksson, "Recurrent venous thromboembolism after deep vein thrombosis: incidence and risk factors," Archives of Internal Medicine, vol. 160, no. 6, pp. 769-774, 2000.

[86] W. H. Geerts, D. Bergqvist, G. F. Pineo et al., "Prevention of venous thromboembolism: American College of Chest Physicians evidence-based clinical practice guidelines (8th edition)," Chest, vol. 133, no. 6, pp. 381S-453S, 2008.

[87] A. Y. Y. Lee, "The role of low-molecular-weight heparins in the prevention and treatment of venous thromboembolism in cancer patients," Current Opinion in Pulmonary Medicine, vol. 9, no. 5, pp. 351-355, 2003.

[88] A. K. Kakkar, S. Haas, H. Wolf, and A. Encke, "Evaluation of perioperative fatal pulmonary embolism and death in cancer surgical patients: the MC-4 cancer substudy," Thrombosis and Haemostasis, vol. 94, no. 4, pp. 867-871, 2005.

[89] G. Petralia, A. McManus, and A. Kakkar, "Thromboprophyalxis in cancer surgery," in Cancer-Associated Thrombosis: New Findings in Translational Science, A. A. Khorana and C. W. Francis, Eds., Informa Healthcare, 2008.

[90] "Coumadin (Warfarin Sodium Tablets, USP) Prescribing Information," Bristol-Myers Squibb Company, Princeton, NJ, USA, 2007, http://packageinserts.bms.com/pi/pi_coumadin.pdf.

[91] L. A. Linkins, "Management of venous thromboembolism in patients with cancer: role of dalteparin," Vascular Health and Risk Management, vol. 4, no. 2, pp. 279-287, 2008. 
[92] A. Y. Y. Lee and M. N. Levine, "Venous thromboembolism and cancer: risks and outcomes," Circulation, vol. 107, no. 23, pp. I17-I21, 2003.

[93] R. D. Bona, K. Y. Sivjee, A. D. Hickey, D. M. Wallace, and S. B. Wajcs, "The efficacy and safety of oral anticoagulation in patients with cancer," Thrombosis and Haemostasis, vol. 74, pp. 1055-1058, 1995.

[94] M. N. Levine, "Managing thromboembolic disease in the cancer patient: efficacy and safety of antithrombotic treatment options in patients with cancer," Cancer Treatment Reviews, vol. 28, no. 3, pp. 145-149, 2002.

[95] A. Falanga and L. Zacharski, "Deep vein thrombosis in cancer: the scale of the problem and approaches to management," Annals of Oncology, vol. 16, no. 5, pp. 696-701, 2005.

[96] L. R. Zacharski, P. Prandoni, and M. Monreal, "Warfarin versus low-molecular-weight heparin therapy in cancer patients," Oncologist, vol. 10, no. 1, pp. 72-79, 2005.

[97] M. Magagnoli, G. Masci, C. Carnaghi et al., "Minidose warfarin is associated with a high incidence of International Normalized Ratio elevation during chemotherapy with FOLFOX regimen," Annals of Oncology, vol. 14, no. 6, pp. 959960, 2003.

[98] M. Magagnoli, G. Masci, L. Castagna, E. Morenghi, and A. Santoro, "High incidence of INR alteration in gastrointestinal cancer patients treated with mini-dose warfarin and 5-fluorouracil-based regimens," Annals of Oncology, vol. 17, no. 1, pp. 174-176, 2006.

[99] G. Giunta, "Adverse interaction between capecitabine and warfarin resulting in altered coagulation parameters: a review of the literature starting from a case report," Journal of Medical Case Reports, vol. 2010, Article ID 426804, 2010.

[100] R. Camidge, B. Reigner, J. Cassidy et al., "Significant effect of capecitabine on the pharmacokinetics and pharmacodynamics of warfarin in patients with cancer," Journal of Clinical Oncology, vol. 23, no. 21, pp. 4719-4725, 2005.

[101] L. V. Moretti and R. O. Montalvo, "Elevated International Normalized Ratio associated with concurrent use of sorafenib and warfarin," American Journal of Health-System Pharmacy, vol. 66, no. 23, pp. 2123-2125, 2009.

[102] K. S. Thomas, A. Billingsley, N. Amarshi, and B. A. Nair, "Elevated international normalized ratio associated with concomitant warfarin and erlotinib," American Journal of Health-System Pharmacy, vol. 67, no. 17, pp. 1426-1429, 2010.

[103] G. Masci, M. Magagnoli, P. A. Zucali et al., "Minidose warfarin prophylaxis for catheter-associated thrombosis in cancer patients: can it be safely associated with fluorouracilbased chemotherapy?" Journal of Clinical Oncology, vol. 21, no. 4, pp. 736-739, 2003.

[104] E. A. Nutescu, "Assessing, preventing, and treating venous thromboembolism: evidence-based approaches," American Journal of Health-System Pharmacy, vol. 64, no. 11, pp. S5S13, 2007.

[105] P. Prandoni, A. Piccioli, and A. Pagnan, "Recurrent thromboembolism in cancer patients: incidence and risk factors," Seminars in Thrombosis and Hemostasis, vol. 29, pp. 3-8, 2003.

[106] J. Hirsh, K. A. Bauer, M. B. Donati, M. Gould, M. M. Samama, and J. I. Weitz, "Parenteral anticoagulants: American College of Chest Physicians evidence-based clinical practice guidelines (8th edition)," Chest, vol. 133, no. 6, pp. 141S159S, 2008.

[107] J. Hirsh, T. E. Warkentin, R. Raschke, C. Granger, E. M. Ohman, and J. E. Dalen, "Heparin and low-molecular-weight heparin: mechanisms of action, Pharmacokinetics, dosing considerations, monitoring, efficacy, and safety," Chest, vol. 114, no. 5, pp. 489S-510S, 1998.

[108] J. Rem, F. Duckert, R. Fridrich, and U. F. Gruber, "Subcutaneous small heparin doses for the prevention of thrombosis in general surgery and urology," Schweizerische Medizinische Wochenschrift, vol. 105, pp. 827-835, 1975.

[109] A. S. Gallus, J. Hirsh, S. E. O’Brien, J. A. McBride, R. J. Tuttle, and M. Gent, "Prevention of venous thrombosis with small, subcutaneous doses of heparin," Journal of the American Medical Association, vol. 235, no. 18, pp. 1980-1982, 1976.

[110] V. V. Kakkar, "Prevention of fatal postoperative pulmonary embolism by low doses of heparin. An international multicentre trial," The Lancet, vol. 2, no. 7924, pp. 45-51, 1975.

[111] T. L. Ortel, "Heparin-induced thrombocytopenia: when a low platelet count is a mandate for anticoagulation," Hematology, pp. 225-232, 2009.

[112] H. R. Büller, G. Agnelli, R. D. Hull, T. M. Hyers, M. H. Prins, and G. E. Raskob, "Antithrombotic therapy for venous thromboembolic disease: the Seventh ACCP Conference on Antithrombotic and Thrombolytic Therapy," Chest, vol. 126, no. 3, pp. 401S-428S, 2004.

[113] S. Haas, H. Wolf, A. K. Kakkar, J. Fareed, and A. Encke, "Prevention of fatal pulmonary embolism and mortality in surgical patients: a randomized double-blind comparison of LMWH with unfractionated heparin," Thrombosis and Haemostasis, vol. 94, pp. 814-819, 2005.

[114] D. Bergqvist, U. S. Burmark, J. Frisell et al., "Low molecular weight heparin once daily compared with conventional lowdose heparin twice daily. A prospective double-blind multicentre trial on prevention of postoperative thrombosis," British Journal of Surgery, vol. 73, pp. 204-208, 1986.

[115] D. Bergqvist, T. Matzsch, U. S. Burmark et al., "Low molecular weight heparin given the evening before surgery compared with conventional low-dose heparin in prevention of thrombosis," British Journal of Surgery, vol. 75, no. 9, pp. 888891, 1988.

[116] M. Samama, P. Bernard, J. P. Bonnardot, S. Combe-Tamzali, Y. Lanson, and E. Tissot, "Low molecular weight heparin compared with unfractionated heparin in prevention of postoperative thrombosis," British Journal of Surgery, vol. 75, no. 2, pp. 128-131, 1988.

[117] A. Leizorovicz, H. Picolet, J. C. Peyrieux, and J. P. Boissel, "Prevention of perioperative deep vein thrombosis in general surgery: a multicentre double blind study comparing two doses of Logiparin and standard heparin. H. B. P. M. Research Group," British Journal of Surgery, vol. 78, pp. 412-416, 1991.

[118] V. V. Kakkar, A. T. Cohen, R. A. Edmonson et al., "Low molecular weight versus standard heparin for prevention of venous thromboembolism after major abdominal surgery. The Thromboprophylaxis Collaborative Group," The Lancet, vol. 341, pp. 259-265, 1993.

[119] B. Boneu, "An international multicentre study: clivarin in the prevention of venous thromboembolism in patients undergoing general surgery. Report of the International Clivarin Assessment Group," Blood Coagulation and Fibrinolysis, vol. 4, no. 1, pp. S21-S22, 1993.

[120] The European Fraxiparin Study (EFS) Group, “Comparison of a low molecular weight heparin and unfractionated heparin for the prevention of deep vein thrombosis in patients undergoing abdominal surgery," British Journal of Surgery, vol. 75, pp. 1058-1063, 1988. 
[121] A. Gallus, J. Cade, P. Ockelford et al., "Orgaran (Org 10172) or heparin for preventing venous thrombosis after elective surgery for malignant disease? A double-blind, randomised, multicentre comparison. ANZ-Organon Investigators' Group," Thrombosis and Haemostasis, vol. 70, pp. 562$567,1993$.

[122] M. T. Nurmohamed, R. Verhaeghe, S. Haas et al., "A comparative trial of a low molecular weight heparin (enoxaparin) versus standard heparin for the prophylaxis of postoperative deep vein thrombosis in general surgery," American Journal of Surgery, vol. 169, no. 6, pp. 567-571, 1995.

[123] P. Mismetti, S. Laporte, J. Y. Darmon, A. Buchmüller, and H. Decousus, "Meta-analysis of low molecular weight heparin in the prevention of venous thromboembolism in general surgery," British Journal of Surgery, vol. 88, no. 7, pp. 913930, 2001.

[124] E. A. Akl, I. Terrenato, M. Barba et al., "Low-molecularweight heparin vs unfractionated heparin for perioperative thromboprophylaxis in patients with cancer: a systematic review and meta-analysis," Archives of Internal Medicine, vol. 168, no. 12, pp. 1261-1269, 2008.

[125] E. A. Akl, N. Labedi, and I. Terrenato, "Low molecular weight heparin versus unfractionated heparin for perioperative thromboprophylaxis in patients with cancer," Cochrane Database of Systematic Reviews, vol. 11, Article ID CD009447, 2011.

[126] D. Bergqvist, U. S. Burmark, P. A. Flordal et al., "Low molecular weight heparin started before surgery as prophylaxis against deep vein thrombosis: 2500 versus $5000 \mathrm{XaI}$ units in 2070 patients," British Journal of Surgery, vol. 82, no. 4, pp. 496-501, 1995.

[127] G. H. Lyman, A. A. Khorana, A. Falanga et al., "American Society of Clinical Oncology Guideline: recommendations for venous thromboembolism prophylaxis and treatment in patients with cancer," Journal of Clinical Oncology, vol. 25, no. 34, pp. 5490-5505, 2007.

[128] M. Mandalà, A. Falanga, and F. Roila, "ESMO Guidelines Working Group. Management of venous thromboembolism (VTE) in cancer patients: ESMO Clinical Practice Guidelines," Annals of Oncology, vol. 22, pp. vi85-vi92, 2011.

[129] C. M. Samama and W. H. Geerts, "Prevention of intraoperative venous thromboembolism: what are the American College of Chest Physicians Evidence-Based Clinical Practice Guidelines (8th edition)?" Annales Francaises d'Anesthesie et de Reanimation, vol. 28, no. 9, pp. S23-S28, 2009.

[130] National Comprehensive Cancer Network Clinical Practice in Oncology, "Venous thromboembolic disease," 2010, http://www.nccn.org/.

[131] D. Farge, C. Durant, S. Villiers et al., "Groupe Francophone Thrombose et Cancer (GFTC). Lessons from French National Guidelines on the treatment of venous thrombosis and central venous catheter thrombosis in cancer patients," Thrombosis Research, vol. 125, supplement 2, pp. S108-S116, 2010.

[132] G. H. Westrich, L. M. Specht, N. E. Sharrock et al., "Pneumatic compression hemodynamics in total hip arthroplasty," Clinical Orthopaedics and Related Research, no. 372, pp. 180191, 2000.

[133] L. J. Petersen, "Anticoagulation therapy for prevention and treatment of venous thromboembolic events in cancer patients: a review of current guidelines," Cancer Treatment Reviews, vol. 35, no. 8, pp. 754-764, 2009.

[134] A. Zalpour, M. H. Kroll, V. Afshar-Kharghan, S. W. Yusuf, and C. Escalante, "Role of factor xa inhibitors in cancer-associated thrombosis: any new data?" Advances in Hematology, vol. 2011, Article ID 196135, 2011.

[135] A. G. Turpie, K. A. Bauer, J. A. Caprini, P. C. Comp, M. Gent, and J. E. Muntz, "Apollo Investigators. Fondaparinux combined with intermittent pneumatic compression vs. intermittent pneumatic compression alone for prevention of venous thromboembolism after abdominal surgery: a randomized, double-blind comparison," Journal of Thrombosis and Haemostasis, vol. 5, pp. 1854-1861, 2007.

[136] G. Agnelli, D. Bergqvist, A. T. Cohen, A. S. Gallus, M. Gent, and PEGASUS investigators, "Randomized clinical trial of postoperative fondaparinux versus perioperative dalteparin for prevention of venous thromboembolism in high-risk abdominal surgery," British Journal of Surgery, vol. 92, pp. 1212-1220, 2005.

[137] T. E. Warkentin, R. J. Cook, V. J. Marder et al., "Anti-platelet factor 4/heparin antibodies in orthopedic surgery patients receiving antithrombotic prophylaxis with fondaparinux or enoxaparin,” Blood, vol. 106, no. 12, pp. 3791-3796, 2005.

[138] M. J. Kovacs, "Successful treatment of heparin induced thrombocytopenia (HIT) with fondaparinux," Thrombosis and Haemostasis, vol. 93, pp. 999-1000, 2005.

[139] T. E. Warkentin, A. Greinacher, A. Koster, A. M. Lincoff, and College of Chest Physicians American, "Treatment and prevention of heparin-induced thrombocytopenia: American College of Chest Physicians Evidence-Based Clinical Practice Guidelines (8th Edition)," Chest, vol. 133, pp. 340S-380S, 2008, Erratum in: Chest, vol, 139, article 1261, 2011.

[140] B. I. Eriksson, O. E. Dahl, H. R. Büller et al., "A new oral direct thrombin inhibitor, dabigatran etexilate, compared to enoxaparin for prevention of throboembolic events following total hip or knee replacement: the BISTRO II randomized trial," Journal of Thrombosis and Haemostasis, vol. 3, pp. 103111, 2005.

[141] B. I. Eriksson, O. E. Dahl, N. Rosencher et al., "Oral dabigatran etexilate vs. subcutaneous enoxaparin for the prevention of venous thromboembolism after total knee replacement: the RE-MODEL randomized trial," Journal of Thrombosis and Haemostasis, vol. 5, pp. 2178-2185, 2007.

[142] B. I. Eriksson, O. E. Dahl, N. Rosencher et al., "Dabigatran etexilate versus enoxaparin for prevention of venous thromboembolism after total hip replacement: a randomised, double-blind, non-inferiority trial," The Lancet, vol. 370, no. 9591, pp. 949-956, 2007.

[143] The RE-MOBLIZE Writing Committee, “The oral thrombin inhibitor dabigatran etexilate vs. the North American enoxaparin regime for the prevention of venous thromboembolism after knee arthroplasty surgery," The Journal of Arthroplasty, vol. 24, pp. 1-9, 2009.

[144] B. I. Eriksson, L. C. Borris, O. E. Dahl et al., "A oncedaily, oral, direct Factor Xa inhibitor, rivaroxaban (BAY 597939), for thromboprophylaxis after total hip replacement," Circulation, vol. 114, no. 22, pp. 2374-2381, 2006.

[145] B. I. Eriksson, L. C. Borris, R. J. Friedman et al., "Rivaroxaban versus enoxaparin for thromboprophylaxis after hip arthroplasty," The New England Journal of Medicine, vol. 358, no. 26, pp. 2765-2775, 2008.

[146] A. K. Kakkar, B. Brenner, O. E. Dahl et al., "Extended duration rivaroxaban versus short-term enoxaparin for the prevention of venous thromboembolism after total hip arthroplasty: a double-blind, randomised controlled trial," The Lancet, vol. 372, no. 9632, pp. 31-39, 2008.

[147] M. R. Lassen, W. Ageno, L. C. Borris et al., "Rivaroxaban versus enoxaparin for thromboprophylaxis after total knee 
arthroplasty," The New England Journal of Medicine, vol. 358, no. 26, pp. 2776-2786, 2008.

[148] A. G. Turpie, M. R. Lassen, B. L. Davidson et al., "Rivaroxaban versus enoxaparin for thromboprophylaxis after total knee replacement (RECORD 4): a randomized trial," The Lancet, vol. 373, pp. 1673-1680, 2009.

[149] X. Jiang, E. J. Crain, J. M. Luettgen, W. A. Schumacher, and P. C. Wong, "Apixaban, an oral direct factor Xa inhibitor, inhibits human clot-bound factor Xa activity in vitro," Thrombosis and Haemostasis, vol. 101, pp. 780-782, 2009.

[150] E. Shantsila and G. Y. H. Lip, "Apixaban, an oral, direct inhibitor of activated Factor Xa," Current Opinion in Investigational Drugs, vol. 9, no. 9, pp. 1020-1033, 2008.

[151] L. Michaels, "Cancer incidence and mortality in patients having anticoagulant therapy," The Lancet, vol. 284, no. 7364, pp. 832-835, 1964.

[152] L. R. Zacharski, W. G. Henderson, F. R. Rickles et al., "Effect of warfarin on survival in small cell carcinoma of the lung," JAMA: Journal of the American Medical Association, vol. 245, pp. 831-835, 1981.

[153] M. Altinbas, H. S. Coskun, O. Er et al., "A randomized clinical trial of combination chemotherapy with and without lowmolecular-weight heparin in small cell lung cancer," Journal of Thrombosis and Haemostasis, vol. 2, pp. 1266-1271, 2004.

[154] A. K. Kakkar, M. N. Levine, Z. Kadziola et al., "Low molecular weight heparin, therapy with dalteparin, and survival in advanced cancer: the fragmin advanced malignancy outcome study (FAMOUS)," Journal of Clinical Oncology, vol. 22, no. 10, pp. 1944-1948, 2004.

[155] C. P. W. Klerk, S. M. Smorenburg, H. M. Otten et al., "The effect of low molecular weight heparin on survival in patients with advanced malignancy," Journal of Clinical Oncology, vol. 23, no. 10, pp. 2130-2135, 2005.

[156] A. Y. Y. Lee, F. R. Rickles, J. A. Julian et al., "Randomized comparison of low molecular weight heparin and coumarin derivatives on the survival of patients with cancer and venous thromboembolism," Journal of Clinical Oncology, vol. 23, no. 10, pp. 2123-2129, 2005.

[157] R. H. Cosgrove, L. R. Zacharski, E. Racine, and J. C. Andersen, "Improved cancer mortality with low-molecularweight heparin treatment: a review of the evidence," Seminars in Thrombosis and Hemostasis, vol. 28, pp. 79-87, 2002.

[158] W. H. Geerts, G. F. Pineo, J. A. Heit et al., "Prevention of venous thromboembolism: the Seventh ACCP Conference on Antithrombotic and Thrombolytic Therapy," Chest, vol. 126, no. 3, pp. 338S-400S, 2004.

[159] A. G. G. Turpie, J. Hirsh, M. Gent, D. Julian, and J. Johnson, "Prevention of deep vein thrombosis in potential neurosurgical patients. A randomized trial comparing graduated compression stockings alone or graduated compression stockings plus intermittent pneumatic compression with control," Archives of Internal Medicine, vol. 149, no. 3, pp. 679-681, 1989.

[160] K. Lacut, L. Bressollette, G. Le Gal et al., "Prevention of venous thrombosis in patients with acute intracerebral hemorrhage," Neurology, vol. 65, no. 6, pp. 865-869, 2005.

[161] Y. Silbersack, B. M. Taute, W. Hein, and H. Podhaisky, "Prevention of deep-vein thrombosis after total hip and knee replacement. Low-molecular-weight heparin in combination with intermittent pneumatic compression," Journal of Bone and Joint Surgery-Series B, vol. 86, no. 6, pp. 809-812, 2004.

[162] P. Roderick, G. Ferris, K. Wilson et al., "Towards evidencebasedguidelines for the prevention of venous thromboembolism: systematic reviews of mechanical methods, oral anticoagulation, dextran and regional anaesthesia as thromboprophylaxis," Health Technology Assessment (Winchester, England), vol. 9, no. 49, pp. 1-78, 2005.

[163] S. V. Amaragiri and T. A. Lees, "Elastic compression stockings for prevention of deep vein thrombosis," Cochrane Database of Systematic Reviews, no. 3, Article ID CD001484, 2000, Update in: Cochrane Database of Systematic Reviews, no. 7, Article ID CD001484, 2010.

[164] P. Wille-Jørgensen, "Prophylaxis of postoperative thromboembolism with a combination of heparin and graduated compression stockings," International Angiology, vol. 15, no. 3, pp. 15-20, 1996.

[165] E. P. Kalodiki, D. A. Hoppensteadt, A. N. Nicolaides et al., "Deep venous thrombosis prophylaxis with low molecular weight heparin and elastic compression in patients having total hip replacement: a randomised controlled trial," International Angiology, vol. 15, no. 2, pp. 162-168, 1996.

[166] R. Ramos, B. I. Salem, M. P. De Pawlikowski, C. Coordes, S. Eisenberg, and R. Leidenfrost, "The efficacy of pneumatic compression stockings in the prevention of pulmonary embolism after cardiac surgery," Chest, vol. 109, no. 1, pp. 82-85, 1996.

[167] P. Wille-Jørgensen, M. S. Rasmussen, B. R. Andersen, and L. Borly, "Heparins and mechanical methods for thromboprophylaxis in colorectal surgery," Cochrane Database of Systematic Reviews, no. 3, Article ID CD001217, 2001.

[168] S. K. Kakkos, J. A. Caprini, G. Geroulakos, A. N. Nicolaides, G. P. Stansby, and D. J. Reddy, "Combined intermittent pneumatic leg compression and pharmacological prophylaxis for prevention of venous thrombo-embolism in high-risk patients," European Journal of Vascular and Endovascular Surgery, vol. 37, no. 3, pp. 364-365, 2009.

[169] P. S. Wells, A. W. A. Lensing, and J. Hirsh, "Graduated compression stockings in the prevention of postoperative venous thromboembolism: a meta-analysis," Archives of Internal Medicine, vol. 154, no. 1, pp. 67-72, 1994.

[170] S. K. Kakkos, J. A. Caprini, G. Geroulakos, A. N. Nicolaides, G. P. Stansby, and D. J. Reddy, "Combined intermittent pneumatic leg compression and pharmacological prophylaxis for prevention of venous thromboembolism in highrisk patients," Cochrane Database of Systematic Reviews, no. 4, Article ID CD005258, 2008.

[171] P. F. Lachiewicz, S. S. Kelley, and L. R. Haden, "Two mechanical devices for prophylaxis of thromboembolism after total knee arthroplasty. A prospective, randomised study," Journal of Bone and Joint Surgery-Series B, vol. 86, no. 8, pp. 11371141, 2004.

[172] R. J. Morris and J. P. Woodcock, "Evidence-based compression: prevention of stasis and deep vein thrombosis," Annals of Surgery, vol. 239, no. 2, pp. 162-171, 2004.

[173] A. J. Comerota, M. L. Katz, and J. V. White, "Why does prophylaxis with external pneumatic compression for deep vein thrombosis fail?" American Journal of Surgery, vol. 164, no. 3, pp. 265-268, 1992.

[174] F. S. Haddad, R. M. Kerry, J. A. McEwen et al., "Unanticipated variations between expected and delivered pneumatic compression therapy after elective hip surgery: a possible source of variation in reported patient outcomes," Journal of Arthroplasty, vol. 16, no. 1, pp. 37-46, 2001.

[175] E. E. Cornwell, D. Chang, G. Velmahos et al., "Compliance with Sequential Compression Device prophylaxis in at-risk trauma patients: a prospective analysis," American Surgeon, vol. 68 , no. 5, pp. 470-473, 2002. 
[176] C. Charalambous, S. Cleanthous, M. Tryfonidis, A. Goel, R. Swindell, and D. Ellis, "Foot pump prophylaxis for deep venous thrombosis - rate of effective usage following knee and hip arthroplasty," International Orthopaedics, vol. 27, no. 4, pp. 208-210, 2003.

[177] A. J. Best, S. Williams, A. Crozier, R. Bhatt, P. J. Gregg, and A. C. W. Hui, "Graded compression stockings in elective orthopaedic surgery. An assessment of the in vivo performance of commercially available stockings in patients having hip and knee arthroplasty," Journal of Bone and Joint Surgery-Series B, vol. 82, no. 1, pp. 116-118, 2000.

[178] D. Bergqvist, G. Agnelli, A. T. Cohen et al., "Duration of prophylaxis against venous thromboembolism with enoxaparin after surgery for cancer," The New England Journal of Medicine, vol. 346, no. 13, pp. 975-980, 2002.

[179] M. S. Rasmussen, L. N. Jorgensen, and P. W. Wille-Jørgensen, "Prolonged thromboprophylaxis with low molecular weight heparin (Dalteparin) after major abdominal surgery: the FAME study," Journal of Thrombosis and Haemostasis, vol. 1, supplement 1, abstract no. OC399, 2003.

[180] V. V. Kakkar, J. L. Balibrea, J. Martınez-Gonza lez, P. Prandoni, and CANBESURE Study Group, "Extended prophylaxis with bemiparin for the prevention of venous thromboembolism after abdominal or pelvic surgery for cancer: the CANBESURE randomized study," Journal of Thrombosis and Haemostasis, vol. 8, pp. 1223-1229, 2010.

[181] P. Varpe, H. Huhtinen, A. Rantala, and J. Grönroos, "Thromboprophylaxis following surgery for colorectal cancer-is it worthwhile after hospital discharge?" Scandinavian Journal of Surgery, vol. 98, no. 1, pp. 58-61, 2009.

[182] J. E. Ansell, "Prophylaxis and treatment of venous thromboembolism in cancer patients: a review," American Journal of Clinical Oncology, vol. 32, no. 4, pp. S8-S12, 2009.

[183] D. W. Harrington, "Choosing the right heparin prophylaxis strategy in medical patients at risk for developing VTE: an evidence-based approach," Hospital Practice (Minneap), vol. 38, pp. 18-28, 2010.

[184] P. S. Wells, J. Hirsh, D. R. Anderson et al., "Accuracy of clinical assessment of deep-vein thrombosis," The Lancet, vol. 345, no. 8961, pp. 1326-1330, 1995.

[185] A. Cogo, A. W. A. Lensing, M. W. M. Koopman et al., "Compression ultrasonography for diagnostic management of patients with clinically suspected deep vein thrombosis: prospective cohort study," British Medical Journal, vol. 316, no. 7124, pp. 17-20, 1998.

[186] S. Schulman, R. J. Beyth, C. Kearon, and M. N. Levine, "Hemorrhagic complications of anticoagulant and thrombolytic treatment: American College of Chest Physicians evidence-based clinical practice guidelines (8th edition)," Chest, vol. 133, no. 6, pp. 257S-298S, 2008.

[187] P. S. Wells, D. R. Anderson, M. Rodger et al., "Evaluation of D-dimer in the diagnosis of suspected deep-vein thrombosis," The New England Journal of Medicine, vol. 349, no. 13, pp. 1227-1235, 2003.

[188] S. Goodacre, A. J. Sutton, and F. C. Sampson, "Meta-analysis: the value of clinical assessment in the diagnosis of deep venous thrombosis," Annals of Internal Medicine, vol. 143, no. 2, pp. 129-139, 2005.

[189] P. R. Eisenberg, L. A. Sherman, J. Perez, and A. S. Jaffe, "Relationship between elevated plasma levels of crosslinked fibrin degradation products (XL-FDP) and the clinical presentation of patients with myocardial infarction," Thrombosis Research, vol. 46, pp. 109-120, 1987.
[190] M. Di Nisio, A. Squizzato, A. W. Rutjes, H. R. Büller, A. H. Zwinderman, and P. M. Bossuyt, "Diagnostic accuracy of D-dimer test for exclusion of venous thromboembolism: a systematic review," Journal of Thrombosis and Haemostasis, vol. 5, pp. 296-304, 2007.

[191] M. Righini, A. Perrier, Moerloose P. De, and H. Bounameaux, "D-Dimer for venous thromboembolism diagnosis: 20 years later," Journal of Thrombosis and Haemostasis, vol. 6, pp. 1059-1071, 2008.

[192] R. Hull, J. Hirsh, and D. L. Sackett, "Clinical validity of a negative venogram in patients with clinically suspected venous thrombosis," Circulation, vol. 64, pp. 622-625, 1981.

[193] U. Albrechtsson and C. G. Olsson, "Thrombotic side effects of lower limb phlebography," The Lancet, vol. 1, no. 7962, pp. 723-724, 1976.

[194] M. S. McLachlan, J. G. Thomson, D. W. Taylor, M. E. Kelly, and D. L. Sackett, "Observer variation in the interpretation of lower limb venograms," American Journal of Roentgenology, vol. 132, pp. 227-229, 1979.

[195] J. J. Cronan and G. S. Dorfman, "Advances in ultrasound images of venous thrombosis," Seminars in Nuclear Medicine, vol. 21, pp. 297-312, 1991.

[196] S. Goodacre, F. Sampson, S. Thomas, E. van Beek, and A. Sutton, "Systematic review and meta-analysis of the diagnostic accuracy of ultrasonography for deep vein thrombosis," BMC Medical Imaging, vol. 5, article 6, 2005.

[197] L. A. Linkins, R. Stretton, L. Probyn, and C. Kearon, "Interobserver agreement on ultrasound measurements of residual vein diameter, thrombus echogenicity and Doppler venous flow in patients with previous venous thrombosis," Thrombosis Research, vol. 117, no. 3, pp. 241-247, 2006.

[198] R. Hull, W. G. van Aken, J. Hirsh, A. S. Gallus, G. Hoicka, and A. G. Turpie, "Impedance plethysmography using the occlusive cuff technique in the diagnosis of venous thrombosis," Circulation, vol. 53, pp. 696-700, 1976.

[199] J. S. Ginsberg, P. S. Wells, J. Hirsh et al., "Reevaluation of the sensitivity of impedance plethysmography for the detection of proximal deep vein thrombosis," Archives of Internal Medicine, vol. 154, no. 17, pp. 1930-1933, 1994.

[200] J. H. Indik and J. S. Alpert, "Detection of pulmonary embolism by D-Dimer assay, spiral computed tomography, and magnetic resonance imaging," Progress in Cardiovascular Diseases, vol. 42, no. 4, pp. 261-272, 2000.

[201] S. M. Thomas, S. W. Goodacre, F. C. Sampson, and E. J. R. van Beek, "Diagnostic value of CT for deep vein thrombosis: results of a systematic review and meta-analysis," Clinical Radiology, vol. 63, no. 3, pp. 299-304, 2008.

[202] C. E. Spritzer, J. J. Norconk, H. D. Sostman, and R. E. Coleman, "Detection of deep venous thrombosis by magnetic resonance imaging," Chest, vol. 104, no. 1, pp. 54-60, 1993.

[203] F. C. Sampson, S. W. Goodacre, S. M. Thomas, and E. J. R. Beek, "The accuracy of MRI in diagnosis of suspected deep vein thrombosis: systematic review and meta-analysis," European Radiology, vol. 17, no. 1, pp. 175-181, 2007.

[204] Institute for Clinical Systems Improvement (ICSI), Venous Thromboembolism Prophylaxis, Institute for Clinical Systems Improvement (ICSI), Bloomington, MN, USA, 2010.

[205] A. A. Khorana, "The NCCN clinical practice guidelines on venous thromboembolic disease: strategies for improving VTE prophylaxis in hospitalized cancer patients," Oncologist, vol. 12, no. 11, pp. 1361-1370, 2007.

[206] G. Agnelli and C. Becattini, "Treatment of DVT: how long is enough and how do you predict recurrence," Journal of Thrombosis and Thrombolysis, vol. 25, no. 1, pp. 37-44, 2008. 
[207] L. S. Elting, C. P. Escalante, C. Cooksley et al., "Outcomes and cost of deep venous thrombosis among patients with cancer," Archives of Internal Medicine, vol. 164, no. 15, pp. 1653-1661, 2004.

[208] N. M. Kuderer, A. A. Khorana, G. H. Lyman, and C. W. Francis, "A meta-analysis and systematic review of the efficacy and safety of anticoagulants as cancer treatment: impact on survival and bleeding complications," Cancer, vol. 110, no. 5, pp. 1149-1161, 2007.

[209] M. Verso, G. Agnelli, S. Bertoglio et al., "Enoxaparin for the prevention of venous thromboembolism associated with central vein catheter: a double-blind, placebo-controlled, randomized study in cancer patients," Journal of Clinical Oncology, vol. 23, no. 18, pp. 4057-4062, 2005.

[210] K. M. J. Brose and A. Y. Y. Lee, "Cancer-associated thrombosis: prevention and treatment," Current Oncology, vol. 15, pp. S58-S67, 2008.

[211] S. I. R. Noble, K. Hood, and I. G. Finlay, "The use of long-term low-molecular weight heparin for the treatment of venous thromboembolism in palliative care patients with advanced cancer: a case series of sixty two patients," Palliative Medicine, vol. 21, no. 6, pp. 473-476, 2007.

[212] F. F. van Doormaal, G. E. Raskob, B. L. Davidson et al., "Treatment of venous thromboembolism in patients with cancer: subgroup analysis of the Matisse clinical trials," Thrombosis and Haemostasis, vol. 101, pp. 762-769, 2009.

[213] S. R. Deitcher, C. M. Kessler, G. Merli et al., "Secondary prevention of venous thromboembolic events in patients with active cancer: enoxaparin alone versus initial enoxaparin followed by warfarin for a 180-day period," Clinical and Applied Thrombosis/Hemostasis, vol. 12, pp. 389-396, 2006.

[214] M. Carrier, G. Le Gal, R. Cho, S. Tierney, M. Rodger, and A. Y. Lee, "Dose escaltation of low molecular weight heparin to manage recurrent venous thromboembolic events despite systemic anticoagulation in cancer patients," Journal of Thrombosis and Haemostasis, vol. 7, pp. 760-765, 2009.

[215] P. K. L. Chin, L. E. L. Beckert, S. Gunningham, A. L. Edwards, and B. A. Robinson, "Audit of anticoagulant thromboprophylaxis in hospitalized oncology patients," Internal Medicine Journal, vol. 39, no. 12, pp. 819-825, 2009.

[216] A. T. Cohen, V. F. Tapson, J. F. Bergmann et al., "Venous thromboembolism risk and prophylaxis in the acute hospital care setting (ENDORSE study): a multinational crosssectional study," The Lancet, vol. 371, no. 9610, pp. 387-394, 2008.

[217] J. F. Bergmann, C. Lloret-Linares, A. Rami et al., "Venous thromboembolism risk and prophylaxis in the acute hospital care setting (ENDORSE study): results obtained in France," La Presse Médicale, vol. 40, pp. e528-e537, 2011.

[218] M. A. Stratton, F. A. Anderson, H. I. Bussey et al., "Prevention of venous thromboembolism: adherence to the 1995 American College of Chest Physicians consensus guidelines for surgical patients," Archives of Internal Medicine, vol. 160, no. 3, pp. 334-340, 2000.

[219] A. K. Kakkar, M. Levine, H. M. Pinedo, R. Wolff, and J. Wonge, "Venous thrombosis in cancer patients: insights from the FRONTLINE survey," Oncologist, vol. 8, no. 4, pp. 381388, 2003.

[220] J. D. Wright, S. N. Lewin, M. Shah et al., "Quality of venous thromboembolism prophylaxis in patients undergoing oncologic surgery," Annals of Surgery, vol. 253, no. 6, pp. 11401146, 2011.

[221] C. Kalka, D. Spirk, K. A. Siebenrock et al., "Lack of extended venous thromboembolism in high risk patients undergoing major orthopaedic or major cancer surgery. Electronic Assessment of VTE Prophylaxis in High Risk Surgical Patients at Discharge from Swiss Hospitals (ESSENTIAL)," Thrombosis and Haemostasis, vol. 102, pp. 56-61, 2009.

[222] A. K. Kakkar, B. L. Davidson, S. K. Haas, and Investigators Against Thromboembolism (INATE) Core Group, "Compliance with recommended prophylaxis for venous thromboembolism: improving the use and rate of uptake of clinical practice guidelines," Journal of Thrombosis and Haemostasis, vol. 2, pp. 221-227, 2004.

[223] L. A. Hindorff, W. Burke, A. M. Laberge et al., "A survey of physicians' knowledge and management of venous thromboembolism," Vascular and Endovascular Surgery, vol. 36, pp. 367-375, 2002.

[224] M. D. Cabana, C. S. Rand, N. R. Powe et al., "Why don't physicians follow clinical practice guidelines?: a framework for improvement," Journal of the American Medical Association, vol. 282, no. 15, pp. 1458-1465, 1999.

[225] R. Selby and W. Geerts, "Prevention of venous thromboembolism: consensus, controversies, and challenges," Hematology, pp. 286-292, 2009.

[226] M. V. Huisman and H. Bounameaux, "Treating patients with venous thromboembolism: Initial strategies and long-term secondary prevention," Seminars in Vascular Medicine, vol. 5, no. 3, pp. 276-284, 2005.

[227] A. J. Unwin, J. R. Jones, and W. J. Harries, "Current UK opinion on thromboprophylaxis in orthopaedic surgery: its use in routine total hip and knee arthroplasty," Annals of the Royal College of Surgeons of England, vol. 77, no. 5, pp. 351354, 1995.

[228] S. Conti and M. Daschbach, "Venous thromboembolism prophylaxis. A survey of its use in the United States," Archives of Surgery, vol. 117, no. 8, pp. 1036-1040, 1982.

[229] Enoxacan Study Group, "Efficacy and safety of enoxaparin versus unfractionated heparin for prevention of deep vein thrombosis in elective cancer surgery: a double-blind randomized multicentre trial with venographic assessment," The British Journal of Surgery, vol. 84, pp. 1099-1103, 1997.

[230] C. Becattini, A. Lignani, and G. Agnelli, "New anticoagulants for the prevention of venous thromboembolism," Drug Design, Development and Therapy, vol. 4, pp. 49-60, 2010.

[231] A. Leizorovicz, A. T. Cohen, A. G. Turpie et al., "Randomized, placebo-controlled trial of dalteparin for the prevention of venous thromboembolism in acutely ill medical patients," Circulation, vol. 110, pp. 874-879, 2004.

[232] A. Y. Lee, M. N. Levine, R. I. Baker, C. Bowden, A. K. Kakkar, and M. Prins, "Randomized Comparison of Low-MolecularWeight Heparin versus Oral Anticoagulant Therapy for the Prevention of Recurrent Venous Thromboembolism in Patients with Cancer (CLOT) Investigators. Low-molecularweight heparin versus a coumarin for the prevention of recurrent venous thromboembolism in patients with cancer," The New England Journal of Medicine, vol. 349, pp. 146-153, 2003.

[233] B. Saraiya and S. Goodin, "Management of venous thromboembolism and the potential to impact overall survival in patients with cancer," Pharmacotherapy, vol. 29, no. 11, pp. 1344-1356, 2009.

[234] K. G. Shojania and J. M. Grimshaw, "Evidence-based quality improvement: the state of the science," Health Affairs, vol. 24, no. 1, pp. 138-150, 2005.

[235] P. P. Dobesh and Z. A. Stacy, "Effect of a clinical pharmacy education program on improvement in the quantity and quality of venous thromboembolism prophylaxis for 
medically ill patients," JMCP: Journal of Managed Care Pharmacy, vol. 11, no. 9, pp. 755-762, 2005.

[236] J. M. Stinnett, R. Pendleton, L. Skordos, M. Wheeler, and G. M. Rodgers, "Venous thromboembolism prophylaxis in medically III patients and the development of strategies to improve prophylaxis rates," American Journal of Hematology, vol. 78, no. 3, pp. 167-172, 2005.

[237] S. L. Cohn, A. Adekile, and V. Mahabir, "Improved use of thromboprophylaxis for deep vein thrombosis following an educational intervention," Journal of Hospital Medicine (Online), vol. 1, no. 6, pp. 331-338, 2006.

[238] E. Sellier, J. Labarere, J. L. Bosson et al., "Effectiveness of a guideline for venous thromboembolism prophylaxis in elderly post-acute care patients: a multicenter study with systematic ultrasonographic examination," Archives of Internal Medicine, vol. 166, pp. 2065-2071, 2006.

[239] P. J. Greco and J. M. Eisenberg, "Changing physicians' practices," The New England Journal of Medicine, vol. 329, no. 17, pp. 1271-1274, 1993.

[240] J. M. Grimshaw, L. Shirran, R. Thomas et al., "Changing provider behavior: an overview of systematic reviews of interventions," Medical Care, vol. 39, no. 8, pp. II2-II45, 2001.

[241] J. D. Winkler, K. N. Lohr, and R. H. Brook, "Persuasive communication and medical technology assessment," Archives of Internal Medicine, vol. 145, no. 2, pp. 314-317, 1985.

[242] H. R. Williams and D. A. Macdonald, "Audit of thromboembolic prophylaxis in hip and knee surgery," Annals of the Royal College of Surgeons of England, vol. 79, no. 1, pp. 55-57, 1997.

[243] P. Durieux, R. Nizard, P. Ravaud, N. Mounier, and E. Lepage, "Clinical decision support system for prevention of venous thromboembolism: effect on physician behavior," Journal of the American Medical Association, vol. 283, no. 21, pp. 28162821, 2000.

[244] W. S. Phillips, J. Smith, M. Greaves, F. E. Preston, and K. S. Channer, "An evaluation and improvement program for inpatient anticoagulant control," Thrombosis and Haemostasis, vol. 77, pp. 283-288, 1997.

[245] Investigators against thromboembolism (INATE), http:// www.inate.org/.

[246] D. Bergqvist, U. S. Burmark, and J. Frisell, "Thromboprophylactic effect of low molecular weight heparin started in the evening before elective general abdominal surgery: a comparison with low-dose heparin," Seminars in Thrombosis and Hemostasis, vol. 16, pp. 19-24, 1990.

[247] J. P. Fricker, Y. Vergnes, R. Schach et al., "Low dose heparin versus low molecular weight heparin (Kabi 2165, Fragmin) in the prophylaxis of thromboembolic complications of abdominal oncological surgery," European Journal of Clinical Investigation, vol. 18, no. 6, pp. 561-567, 1988.

[248] J. E. Godwin, P. Comp, B. Davidson, and M. Rossi, "Comparison of the efficacy and safety of subcutaneous Rd Heparin vs subcutaneous unfractionated heparin for the prevention of deep-vein thrombosis in patients undergoing abdominal or pelvic-surgery for cancer," Thrombosis and Haemostasis, vol. 69, article 647, 1993.

[249] R. S. McLeod, W. H. Geerts, K. W. Sniderman et al., "Canadian ColorectalSurgery DVT Prophylaxis Trial investigators. Subcutaneous heparin versus low-molecular-weightheparin as thromboprophylaxis in patientsundergoing colorectal surgery: results of thecanadian colorectal DVT prophylaxis trial: arandomized, double-blind trial," Annals of Surgery, vol. 233, pp. 438-444, 2001.
[250] H. Onarheim, T. Lund, A. Heimdal, and B. A. Arnesjø, "Low molecular weight heparin (KABI 2165) for prophylaxis of postoperative deep venous thrombosis," Acta Chirurgica Scandinavica, vol. 152, pp. 593-596, 1986. 


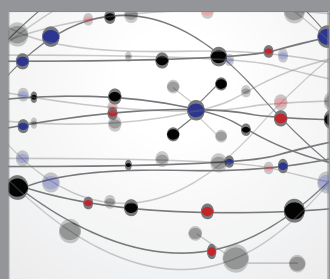

The Scientific World Journal
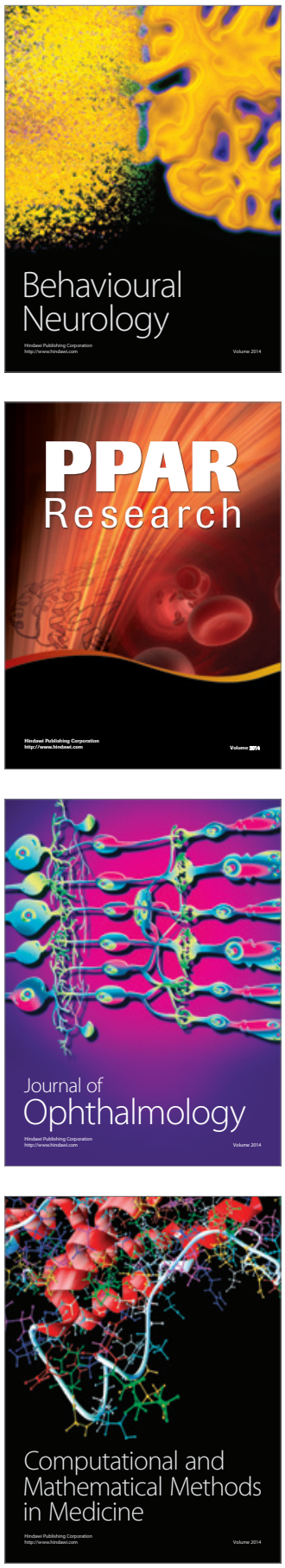

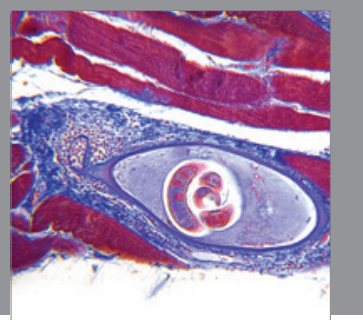

Gastroenterology

Research and Practice
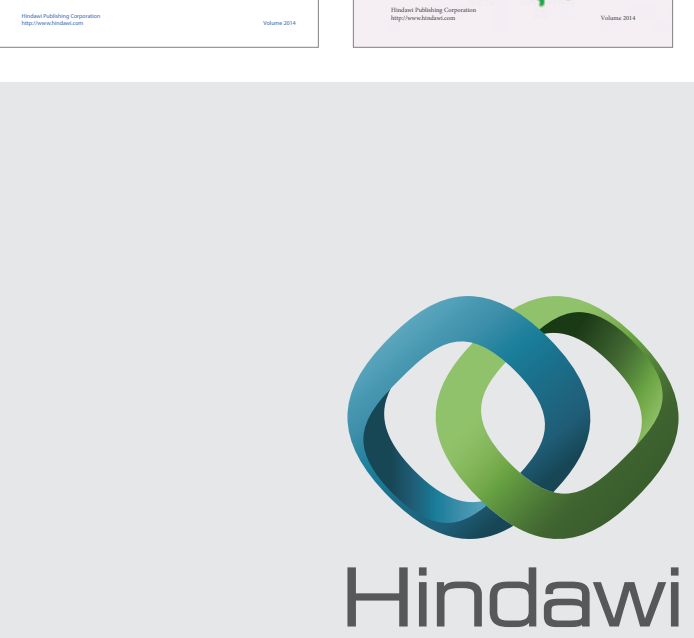

Submit your manuscripts at

http://www.hindawi.com
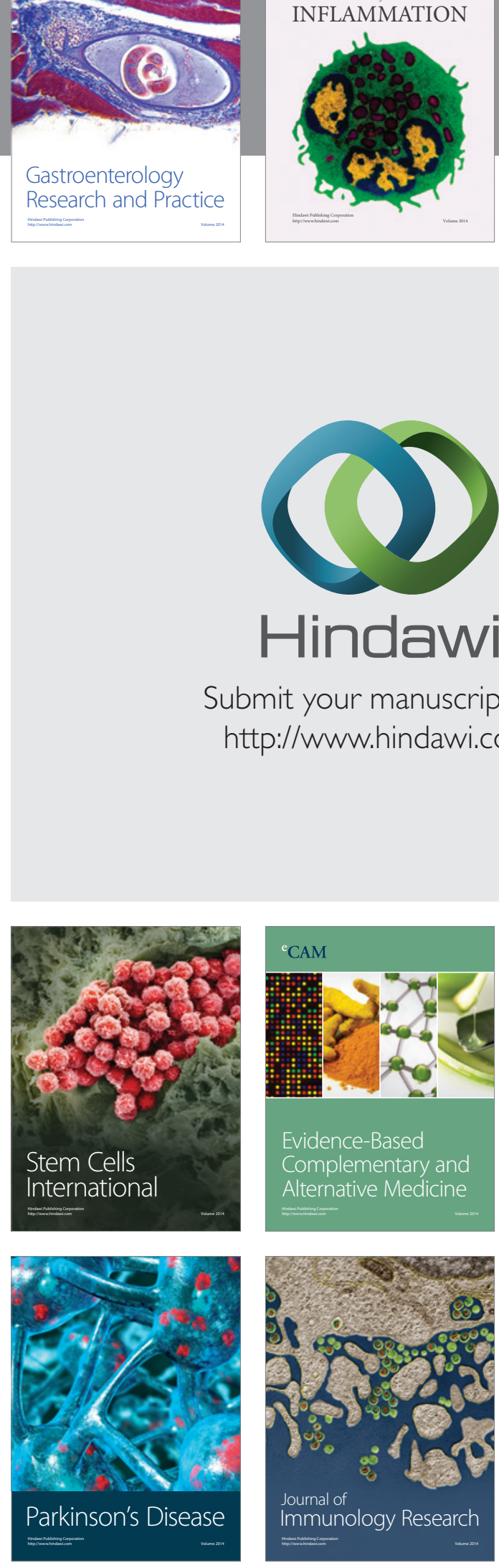

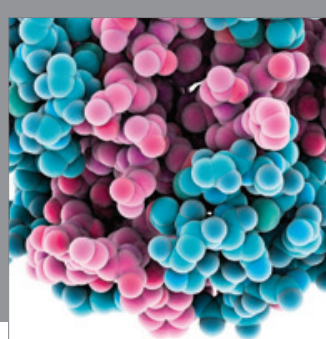

Diabetes Research
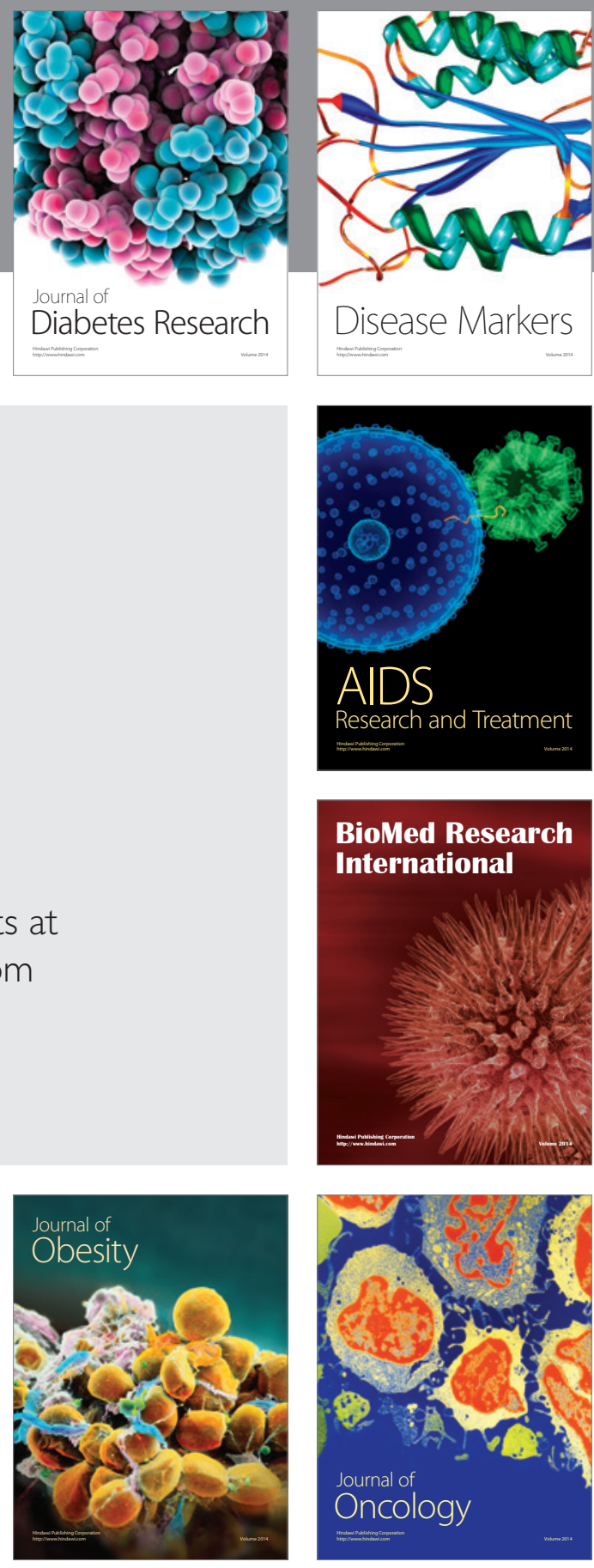

Disease Markers

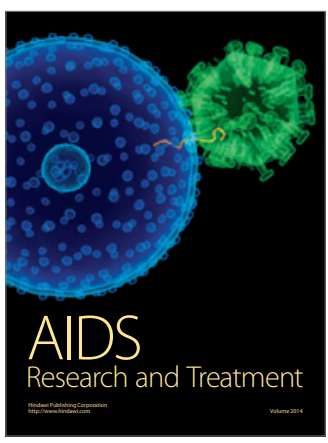

BioMed Research

International
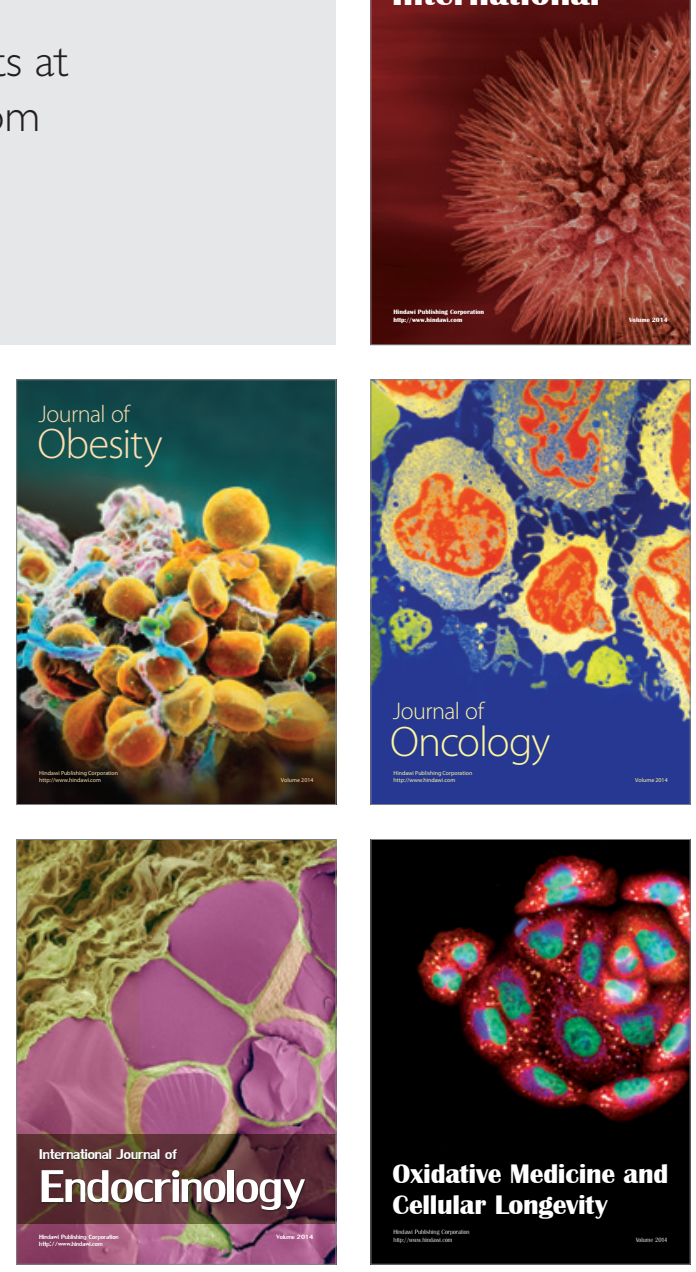